\title{
The importance of the inelastic and elastic structure of the crust in constraining glacial density, mass change, and isostatic adjustment from geodetic observations in southeast Alaska
}

\author{
William Durkin ${ }^{1}$, Samuel Kachuck ${ }^{2,3}$, Matthew Pritchard ${ }^{1}$ \\ ${ }^{1}$ Earth and Atmospheric Sciences Department, Cornell University, Ithaca, New York, USA \\ ${ }^{2}$ Department of Physics, Cornell University, Ithaca, New York, USA \\ ${ }^{3}$ Department of Climate and Space Science and Engineering, University of Michigan, Ann Arbor, \\ Michigan, USA
}

This is the author manuscript accepted for publication and has undergone full peer review but has not been through the copyediting, typesetting, pagination and proofreading process, which may lead to differences between this version and the Version of Record. Please cite this article as doi: 10.1029/2018JB016399

This article is protected by copyright. All rights reserved. 


\begin{abstract}
Elastic deformation of the solid Earth in response to ice mass loss offers a promising constraint on the density of glacial material lost. Further, the elastic response to modern deglaciation is important to constrain for studies of glacial isostatic adjustment to determine the mantle's structure and rheology. Models of this elastic uplift are commonly based on the 1D, seismically derived global average Preliminary Reference Earth Model (PREM) and typically neglect uncertainties that can arise from regional differences in elastic structure from that of the global average, lateral heterogeneities within the region, and inelastic behavior of the crust. We quantify these uncertainties using an ensemble of 1D local elastic structure models and empirical relations for the effects of inelasticity in the upper $\sim 10 \mathrm{~km}$ of the crust. In southeast Alaska, modeling elastic uplift rates with local elastic structures results in up to a $20-40 \%$ difference from those modeled with PREM. Although these differences are limited to regions near to ice covered areas, they are comparable to the differences in uplift rates expected from the loss of firn vs loss of ice. Far from ice covered areas, where most of the region's GPS observations were made, these differences become insignificant and do not affect previous GIA studies in the region. The methods presented here are based on globally available LITHO1.0 seismic model and open source software, and the approach of using an ensemble of 1D elastic structures can be easily adapted to other regions around the world.
\end{abstract}

\title{
1 Introduction
}

Glaciers, icefields, and ice sheets across the world can gain and lose several to 100's of gigatonnes of mass on seasonal and annual time scales [e.g., Gardner et al., 2013; Luthcke et al., 2013; Shepherd et al., 2018], evoking a linear, elastic response from the solid Earth at rates on the scale of millimeters to centimeters per year [e.g., Larsen et al., 2005; Khan et al., 2007; Compton et al., 2017]. Geodetic observations of this elastic deformation may be used to investigate rates of deglaciation [e.g., Zhao et al., 2014], dynamic glacier processes [e.g., Bevan et al., 2015; Adhikari et al., 2017], and the rheological structure of the Earth's interior [e.g., Auriac et al., 2013].

When widespread deglaciation occurs at decadal to centennial time scales in regions underlain by a low viscosity asthenosphere $\left(10^{18}-10^{19} \mathrm{~Pa} \mathrm{~s}\right)$, such as in Iceland [Auriac et al., 2013], Patagonia [Lange et al., 2014], southeast Alaska [Larsen et al., 2005], and regions of West Antarctica [Nield et al., 2014; Barletta et al., 2018] the elastic deforma- 
tion is superimposed on to deformation caused by the viscous relaxation of the mantle (i.e., glacial isostatic adjustment or GIA). Once the elastic component is identified and constrained, the viscous deformation may be used to infer rheological parameters of the solid Earth such as the elastic thickness of the lithosphere and viscosity of the mantle, which can be difficult to constrain through other geophysical techniques. Further, these regions have other deformation processes occurring, for example tectonic [e.g., Sauber and Molnia, 2004; Elliott et al., 2010], magmatic [e.g., Spaans et al., 2015], and hydrologic loading [e.g., Drouin et al., 2016]. Constraining the elastic deformation from deglaciation is critical for partitioning the observed deformation field into these other sources of deformation.

In regions where continuous crustal deformation time series are available, long-term viscous deformation may sometimes be separated from the instantaneous elastic response to ice mass changes by carefully removing long-term trends from higher frequency changes [e.g., Wahr et al., 2013]. However, in regions with high rates of GIA where the viscous response times are decadal to centennial [e.g., Barletta et al., 2018], or in regions with accelerating ice loss [e.g., Khan et al., 2007; Compton et al., 2015], it can be difficult to distinguish between the elastic and viscous components of deformation in this way. Often, GIA is inferred by first modeling the elastic deformation resulting from contemporary deglaciation using estimates of ice mass balance to load a halfspace or a spherical, layered Earth and removing this model from observations of the total uplift, leaving the viscous component of deformation as the residual [e.g., Sato et al., 2011; Lange et al., 2014].

The propagation of biases and uncertainties in ice mass balance estimates used to model elastic deformation can directly impact the viscous deformation that is inferred. For example, in southeast Alaska, Larsen et al. [2005] estimated that $20 \%$ of the uplift observed in southeast Alaska can be described by the elastic response to the average ice loss between the mid-1950s and mid-1990s, with a mean date in the 1970s [Arendt et al., 2002]. Using updated ice-thinning rates with mean dates in the mid-1980s [Larsen et al., 2007], Sato et al. [2011] found that modeled elastic uplift could account for $\sim 26 \%$ of the total uplift and result in a $\sim 1.5 \mathrm{x}$ increase in the estimate of asthenospheric viscosity. However, ice thinning rates estimated by Larsen et al. [2007] are derived from an elevation time series in which the latest elevations come from an under-corrected SRTM DEM, resulting in overly negative mass loss rates [Berthier et al., 2018], and elastic uplift rates 
modeled using this time series [e.g., Sato et al., 2011] may similarly be overestimated. Moreover, while Sato et al. [2011] used ice-thinning rates with median dates in the mid1980s to model the elastic uplift occurring during the period GPS observations were made during the years 1996-2006 (mean epoch of 2003.5), ideally the ice-thinning rates should be coterminous with the period of observation. Reducing the propagation of biases in ice mass balance estimates and improved alignment with deformation observations could help to better resolve other, larger uncertainties in constraining mantle rheology, such as the history of prior ice loss [e.g., Nield et al., 2016] and the constitutive equations describing mantle rheology [e.g., Steffen and $W u, 2011]$.

Uncertainties and biases associated with the Earth model used when estimating elastic deformation could also impact both glaciological investigations and inferred GIA deformation, but have had less investigation. In studies of ice mass balance and regional GIA, a common choice for the elastic Earth model is the radially symmetric, seismically derived, global average Preliminary Reference Earth model [PREM; Dziewonski and Anderson, 1981]. Recently Drouin et al. [2016] and Compton et al. [2017] found that to match modeled elastic deformation of seasonal mass balance changes of Icelandic icecaps with observed uplift required scaling the elastic response calculated using PREM by a factor of $\sim 2$, calling into question the appropriateness of using the globally-averaged elastic structure to represent a volcanic region such as Iceland. Centers of regional GIA and contemporary deglaciation are typically mountainous aggregates of different geologic terrains, often volcanic, and may not be well represented by a single 1D globally-averaged model of elastic structure.

Site-specific elastic structures constrained by seismology may be used [e.g., Nielsen et al., 2013], however crustal material may not behave as elastically under glacial loading as it does during seismic wave propagation. In the upper $\sim 10 \mathrm{~km}$ of the crust, where low confining pressures allow rocks to be porous and fractured, a range of inelastic processes dependent on the frequency and amplitude of strain can dissipate elastic energy [e.g., Cheng and Johnston, 1981; Tutuncu et al., 1998]. The presence of fluids can relax shear stresses, and flow between pores and fractures of varying compliance can viscously dissipate strain energy as heat [e.g., Carcione et al., 2018]. Inelastic processes may occur even in the absence of fluids, such as during the formation and propagation of interand intra-granular fractures as well as slip along fractures and grain boundaries [Brantut et al., 2013; Wong and Baud, 2012]. At the periods $\left(10^{-2}-10^{2}\right.$ seconds) and am- 
plitudes $\left(10^{-5}\right)$ of strain characteristic of seismic wave propagation, these inelastic effects are small and the upper crust is well approximated as a purely elastic medium. But at larger strain amplitudes applied at periods of $\sim 10^{3}$ seconds and longer, inelastic deformation has the effect of reducing the apparent elastic moduli of the material [e.g., Cheng and Johnston, 1981; Johnson and Rasolofosaon, 1996; Tutuncu et al., 1998]. The attenuation of elastic strain energy in the presence of fluids can be described by various analytical models [e.g., Carcione et al., 2018], however inelasticity in dry rocks remains difficult to describe due to the complex physical processes involved and strong dependence on lithology and environmental conditions [Brantut et al., 2013]. A more common approach is to empirically relate a material's 'dynamic' Young's modulus found acoustically to the 'static' Young's modulus derived from the stress-strain curves found from triaxial deformation experiments performed on rock samples [e.g., King, 1983; Ameen et al., 2009; Najibi et al., 2015]. The static-dynamic ratios measured this way can be small [ 0.4, e.g., Cheng and Johnston, 1981]. This introduces an additional source of uncertainty worth considering, particularly when modeling near-field elastic deformation which is sensitive to the rheology of the upper crust.

In an ideal scenario, these complex regions would be modeled using a site-specific, laterally variable, 3D elastic structure. However this is not practical at the time of writing as the regions' 3D structures are not well constrained and modeling elastic uplift rates from such structures would be computationally expensive given their large areas and, presumably, small scale variations. To test the sensitivity of elastic deformation from hydrologic loading to variations in the crust, Dill et al. [2015] modified the upper portion of PREM with an ensemble of crustal models [Tesauro et al., 2012]. We adopt a similar approach and use the global seismic density and velocity model LITHO1.0 [Pasyanos et al., 2014] to construct an ensemble of 1D models representing the variations of crustal structure within southeast Alaska. We consider empirical static-dynamic relations to test the importance of considering inelasticity in the crust, and model the elastic deformation using this ensemble to bound the uncertainties due to variations in crustal structure. In addition, we are able to use this opportunity to update the elastic thinning rates to more closely match the 1996-2006 observation time of the southeast Alaska campaign GPS dataset [Elliott et al., 2010]. While the focus of this study is on southeast Alaska, the use of the global LITHO1.0 model makes our approach easily adaptable to other regions around the world. 


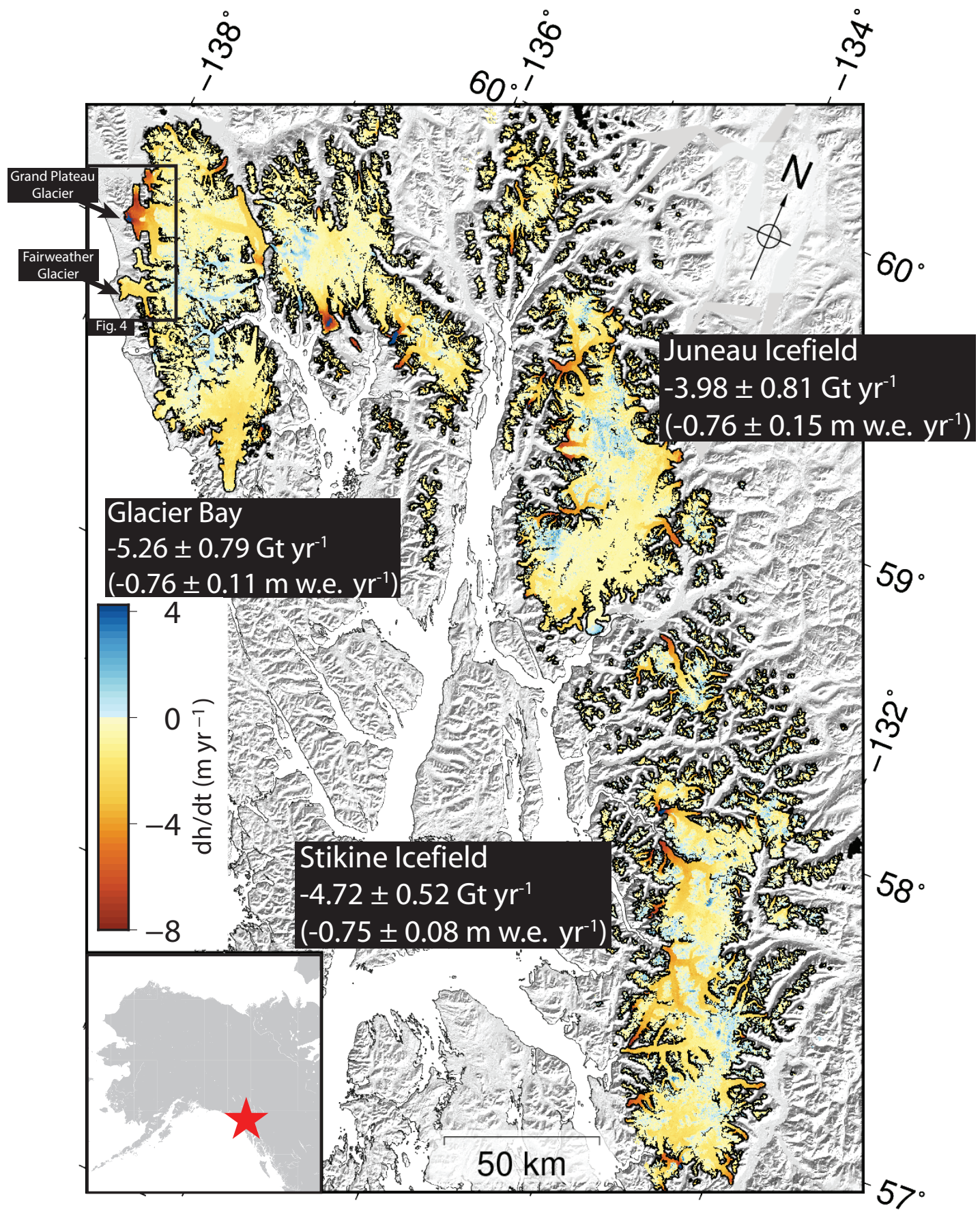

Figure 1. Ice thinning rates of the Stikine Icefield, Juneau Icefield, and Glacier Bay region estimated using the SRTM DEM, ArcticDEM, and ASTER DEMs spanning the years 2000-2017. The SRTM DEM has been corrected for radar penetration into snow and ice (see Section 1.1 of the supplementary material). Mass balance estimates of the Stikine and Juneau icefields are updates of previous work by Melkonian et al. [2016] and Melkonian et al. [2014], respectively. The black box in the upper left corner outlines the region described in Figure 4. 


\section{Study Area}

The Stikine Icefield, Juneau Icefield, and Glacier Bay region (Figure 1) comprise an area of $\sim 17,000 \mathrm{~km}^{2}$, or $20 \%$ of the total glaciated area of Alaska and neighboring Canada [Pfeffer et al., 2014]. They are the southernmost glacier complexes in Alaska, and melt across all elevations has been observed during summer months at the Juneau and Stikine icefields [Smith et al., 1997; Ramage et al., 2000]. Annual melt rates for the Juneau and Stikine icefields between years 2000-2016 were $-0.68 \pm 0.15$ m w.e. $\mathrm{yr}^{-1}$ and $-0.83 \pm 0.12 \mathrm{~m}$ w.e. $\mathrm{yr}^{-1}$, respectively [Berthier et al., 2018], similar to the average mass balance of all Alaskan glaciers between 1994-2015 [-0.94 \pm 0.14 m w.e. $\mathrm{yr}^{-1}$; Larsen et al., 2015], while that of the Glacier Bay region between 1995-2011 [-0.6 \pm 0.1 m w.e.yr ${ }^{-1}$; Johnson et al., 2013] was significantly less negative than the Alaska-wide average. This annual removal of several gigatonnes of mass across each of these glacier complexes elicits the elastic uplift of the solid Earth at rates up to $10 \mathrm{~mm} \mathrm{yr}^{-1}$ [Sato et al., 2011]. Viscous uplift rates of up to $10-20 \mathrm{~mm} \mathrm{yr}^{-1}$ emanate from Glacier Bay in response to the collapse of the Glacier Bay Icefield, which spanned an area of $5 \times 10^{3} \mathrm{~km}^{2}$, reached thicknesses of up to $1.5 \mathrm{~km}$, and lost $\sim 3,500 \mathrm{Gt}$ between the years 1770-1950 [Larsen et al., 2005]. In contrast to Hudson Bay, where the GIA response to collapse of the Laurentide Ice Sheet following the last glacial maximum ( $\sim 20,000$ years ago) drives present day uplift rates of up to $10 \mathrm{~mm} \mathrm{yr}^{-1}$ [e.g., Sella et al., 2007], the present day uplift rate in response to the collapse of the Cordilleran Ice Sheet following the last glacial maximum is more subdued, at 1-2 $\mathrm{mm} \mathrm{yr}^{-1}$ [Larsen et al., 2005]. Taken in aggregate, present day viscoelastic uplift rates peak at $\sim 30 \mathrm{~mm} \mathrm{yr}^{-1}$ centered near Glacier Bay [Larsen et al., 2005; Elliott et al., 2010].

\section{Data and Methods}

\subsection{Ice Mass Balance}

We estimate ice mass balance using a weighted linear regression on a time series of stacked DEMs. These methods were developed by previous studies [e.g., Nuimura et al., 2012; Willis et al., 2012; Melkonian et al., 2014; Wang and Kääb, 2015; Berthier et al., 2016] and only the general procedure is outlined here with greater explanation and discussion provided in the supplementary materials [Gardelle et al., 2012; Dehecq et al., 2016]. We construct an ice-elevation time series composed of SRTM, ArcticDEM, Advanced Space- 
borne Thermal Emission and Reflection Radiometer (ASTER) DEMs. ASTER DEMs are downloaded pre-made by the NASA/USGS operated Land Process Distributive Active Archive Center(LDAAP), and cloudy images are manually removed. A total of 358 ASTER DEMs cover the study area, spanning July 2000 - May 2017 with an average of 15 ASTER elevations covering each pixel. ArcticDEM strips were derived from $\sim 0.5 \mathrm{~m}$ resolution stereoscopic imagery from Digital Globe and made available through the National Science Foundation and National Geospatial Intelligence Agency as $2 \mathrm{~m}$ resolution DEMs using the Surface Extraction with TIN-based Search-space Minimization (SETSM) method [https://www.pgc.umn.edu/data/arcticdem; Noh and Howat, 2015]. ArcticDEM strips covering the study area total in 401 DEMs that span the time period October 2008 - September 2016 with an average density of 2 ArcticDEM elevations per pixel. We downsample ArcticDEM strips to $30 \mathrm{~m}$ resolution and coregister both ArcticDEM and ASTER DEMs to off-ice pixels in the SRTM DEM using "PC_align" in the Ames Stereo Pipeline toolkit [Moratto et al., 2010]. Off-ice pixels are identified using the Randolph Glacier Inventory version 5 [Pfeffer et al., 2014]. Each DEM is assigned $1 \sigma$ vertical uncertainty as the standard deviation between the off-ice pixels of it and the SRTM DEM. We estimate ice elevation change rates $\left(\frac{d h}{d t}\right)$ using a linear regression on our elevation time series in which each elevation is weighted by the inverse of its uncertainty [e.g., Melkonian et al., 2014; Willis et al., 2012].

\subsection{Elastic Uplift Rates, Inelasticity, and Uncertainties}

We use an ensemble of seismic velocity models to quantify the uncertainty associated with representing a geologically variable region as a spherically symmetric model. This ensemble of models is based on LITHO1.0 [Pasyanos et al., 2014], a collection of seismically constrained estimates of density, $\mathrm{P}$-, and S-wave velocities that are globally available at $1^{\circ}$ postings [Pasyanos et al., 2014]. Each LITHO1.0 1D profile has defined sublayers that include ice, water, between one and three sediment layers, an upper, middle and lower crust, and the lithospheric mantle. Excluding profiles that contain a water layer (i.e., profiles that are centered in the ocean), we consider 42 profiles between $59^{\circ}-61^{\circ} \mathrm{N}$ longitude and $130^{\circ}-139^{\circ} \mathrm{W}$ latitude (Figure $2 \mathrm{~A}$ ).

To estimate the effects of inelasticity in the upper crust to a first-order, we use empirical relations fit by Yale et al. [2017] to the static-dynamic ratios of Young's moduli $\left(\mathrm{E}_{S} / \mathrm{E}_{D}\right)$ found from triaxial strain experiments of a combined 35 studies, described in 
Eq. 1. Many of the studies found in literature concerning correlations between $\mathrm{E}_{S}$ and $\mathrm{E}_{D}$ are conducted by the petroleum engineering community for the purpose of modeling the static response of hydrocarbon reservoirs. The triaxial strain experiments considered by Yale et al. [2017] reflect these conditions. Confining pressures vary between 0-100 MPa (corresponding to depths of $0-5 \mathrm{~km}$ in the crust) and temperatures between $20-170^{\circ} \mathrm{C}$. The impacts of confining pressure or the presence of fluids on the static to dynamic ratios are not controlled for, rather, static-to-dynamic ratios are separated by rock type. Yale et al. [2017] found the following relations for soft sedimentary rocks (e.g., unconsolidated sands and shales), hard sedimentary rocks (e.g., tight sandstones, shales, and carbonates), and igneous/metamorphic rocks

$$
E_{S}=\left\{\begin{array}{cc}
5.796 \times 10^{-3} E_{D}{ }^{2}+0.1587 E_{D}+0.1756 & \text { soft sedimentary } \\
0.8353 E_{D}-4.283 & \text { hard sedimentary } \\
1.1027 E_{D}-12.639 & \text { igneous/metamorphic }
\end{array}\right.
$$

where the demarcation between soft and hard sedimentary lithologies is defined by Yale et al. [2017] as $\mathrm{E}_{S} \sim 10-15$ GPa. Table 1 shows the minimum and maximum $\mathrm{E}_{D}$ of each LITHO1.0 sublayer for the ensemble of 42 profiles and its lithology classification for estimating $\mathrm{E}_{S}$ from Eq. 1. Figure $2 \mathrm{~B}$ shows the ratio $\mathrm{E}_{S} / \mathrm{E}_{D}$ estimated from Table 1 and Eq. 1. For $\mathrm{E}_{D}>123 \mathrm{GPa}$, this ratio becomes greater than 1. This is a non-physical and unexpected result, and we set the maximum $\mathrm{E}_{S} / \mathrm{E}_{D}$ value to 1 . The static bulk and static shear moduli are calculated from $\mathrm{E}_{S}$ while the Poisson's ratio is unmodified.

As confining pressure increases, pores and fractures in rocks begin to close, decreasing the differences between the static and dynamic moduli [e.g., Asef and Najibi, 2013], and $\mathrm{E}_{S}$ has been observed to converge to $\mathrm{E}_{D}$ at depths of 10-15 $\mathrm{km}$ [Cheng and Johnston, 1981]. The inelastic corrections in Eq. 1 are based on laboratory experiments conducted at a narrow range of confining pressures $0-100 \mathrm{MPa}$, or the upper $\sim 5 \mathrm{~km}$ of the crust [Yale et al., 2017]. We must take care that applying Eq. 1 to the LITHO1.0 ensemble does not yield static-dynamic ratios that are implausibly small at too great a depth. Figure 8 of the supplementary material shows the scaling factor plotted against depth for each of the 42 LITHO1.0 structures. At a depth of $3.1 \mathrm{~km}$, the smallest $\mathrm{E}_{S} / \mathrm{E}_{D}$ in the ensemble is 0.75 to 0.90 , and beyond depths of $10 \mathrm{~km}$ is no lower than 0.95 . This is consistent with the Es/Ed of 0.9 found by Cheng and Johnston [1981] for granite at con- 


\begin{tabular}{c|c|c} 
LITHO1.0 Sublayer & $\mathrm{E}_{D}(\mathrm{GPa})$ & Yale et al. [2017] lithology \\
\hline sedimentary layer 1 & $2.6-6.7$ & soft sedimentary \\
\hline sedimentary layer 2 & $28.0-41.8$ & hard sedimentary \\
sedimentary layer 3 & $52.7-52.7$ & \\
\hline upper crust & $74.8-96.2$ & igneous/metamorphic \\
middle crust & $89.3-111.2$ & \\
lower crust & $111.2-138.0$ & \\
lithospheric mantle & $172.0-183.6$ &
\end{tabular}

Table 1. Sublayer structure of the LITHO1.0 model and the range of dynamic Young's moduli $\left(\mathrm{E}_{D}\right)$ of each sublayer for the ensemble of 42 elastic structures (Figure 2). Each sublayer is assigned a lithologic classification from Yale et al. [2017] for use with Eq. 1.

fining pressures equivalent to depths of 12-13 km. Differences between the static and dynamic moduli of less than $5 \%$ at depths beyond $10 \mathrm{~km}$ are negligibly small for the purposes of this study.

Each of the elastic structures in our ensemble is used to describe a purely elastic Earth with radially symmetric material parameters. We use the open-source giapy [Kachuck, 2018] to calculate the load Love number solutions to the equations of motion for each of these models from the core-mantle boundary to the surface in response to the application of a spherical harmonic load, as described in Farrell [1972] and Cathles [1975]. Load Love numbers computed using the elastic structure described by PREM using giapy match well with those calculated Pan et al. [2015] (Figure 5 of the supplementary material). Load Love numbers are calculated for each LITHO1.0-based elastic structures to a harmonic degree of 150,000 (Figure 6 of the supplementary material), a sufficiently high value for the purposes of this study [Section 3 of the supplementary material; Jeans, 1923; Bevis et al., 2016].

We downsample gridded estimates of $\frac{d h}{d t}$ (Figure 1) to a lower resolution between $0.0025^{\circ}(228 \mathrm{~m})-0.01^{\circ}(1.11 \mathrm{~km})$ to avoid the high computing costs of modeling elastic deformation with $\frac{d h}{d t}$ at its native $90 \mathrm{~m}$ resolution. Histograms in Figure 3 show how sampling $\frac{d h}{d t}$ of the Glacier Bay, Juneau, and Stikine Icefields is affected by the method of sampling (average, median, and nearest neighbor) and the sampling resolution. Com- 

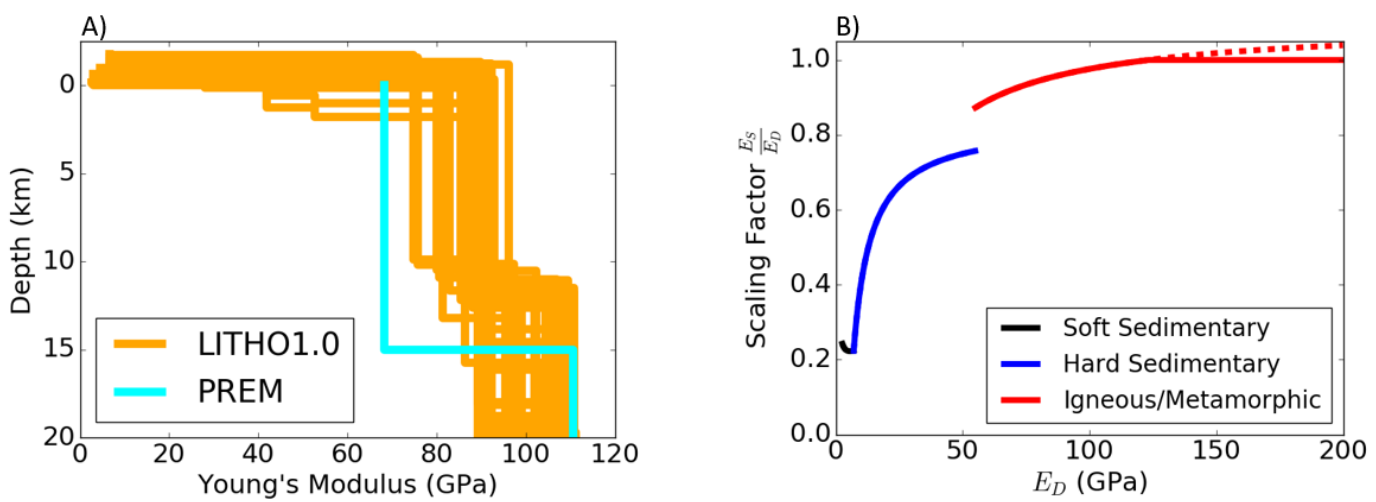

Figure 2. A) Dynamic Young's moduli of the PREM global Earth model (cyan) and the ensemble of LITHO1.0 models used in this study (orange). LITHO1.0 profiles are sampled at a $1^{\circ}$ spacing between $59^{\circ}-61^{\circ} \mathrm{N}$ and $130^{\circ}-139^{\circ} \mathrm{W}$, with profiles sampling the ocean omitted.

B) Piecewise functions of the ratio of static and dynamic Young's moduli $\left(\frac{E_{S}}{E_{D}}\right)$ as a function of the dynamic Young's modulus. Scaling functions for soft sedimentary (black), hard sedimentary (blue), and igneous/metamorphic (red) lithologies are from Yale et al. [2017] and shown in Eq. 1.

pared to the $\frac{d h}{d t}$ at its native resolution, sampling using the average or median results in an overly-positive $\frac{d h}{d t}$ distribution that is accompanied by modest improvements as the sampling resolution increases. Using the nearest neighbor sampling method, the $\frac{d h}{d t}$ distribution converges to the native-resolution $\frac{d h}{d t}$ distribution as the sampling resolution increases (Figure 3C). We therefore sample the $\frac{d h}{d t}$ using the nearest neighbor method to create 456,420 evenly spaced, non-overlapping discs $0.0025^{\circ}$ in diameter.

The collection of $0.0025^{\circ}$ diameter discs are converted from ice thinning rates to mass change rates using a density of $850 \mathrm{~kg} \mathrm{~m}^{-} 3$ [Huss, 2013] and scaled by a factor of $4 / \pi$ to account for the missing volume between each disc. The Green's function computation and convolution of the disc loads for the space-domain response are performed using the Regional ElAstic Rebound calculator [REAR; Melini et al., 2015] using the Legendredomain load Love numbers computed using giapy. These steps are repeated after scaling all models for inelasticity using Eq. 1. We calculate the average of our elastic uplift rate ensemble $\left(\dot{\epsilon}_{L I T H O}\right)$ on a pixel-by-pixel basis as

$$
\dot{\epsilon}_{L I T H O}(x, y)=\frac{\sum_{i=1}^{N} \dot{\epsilon}_{i}(x, y)}{N}
$$



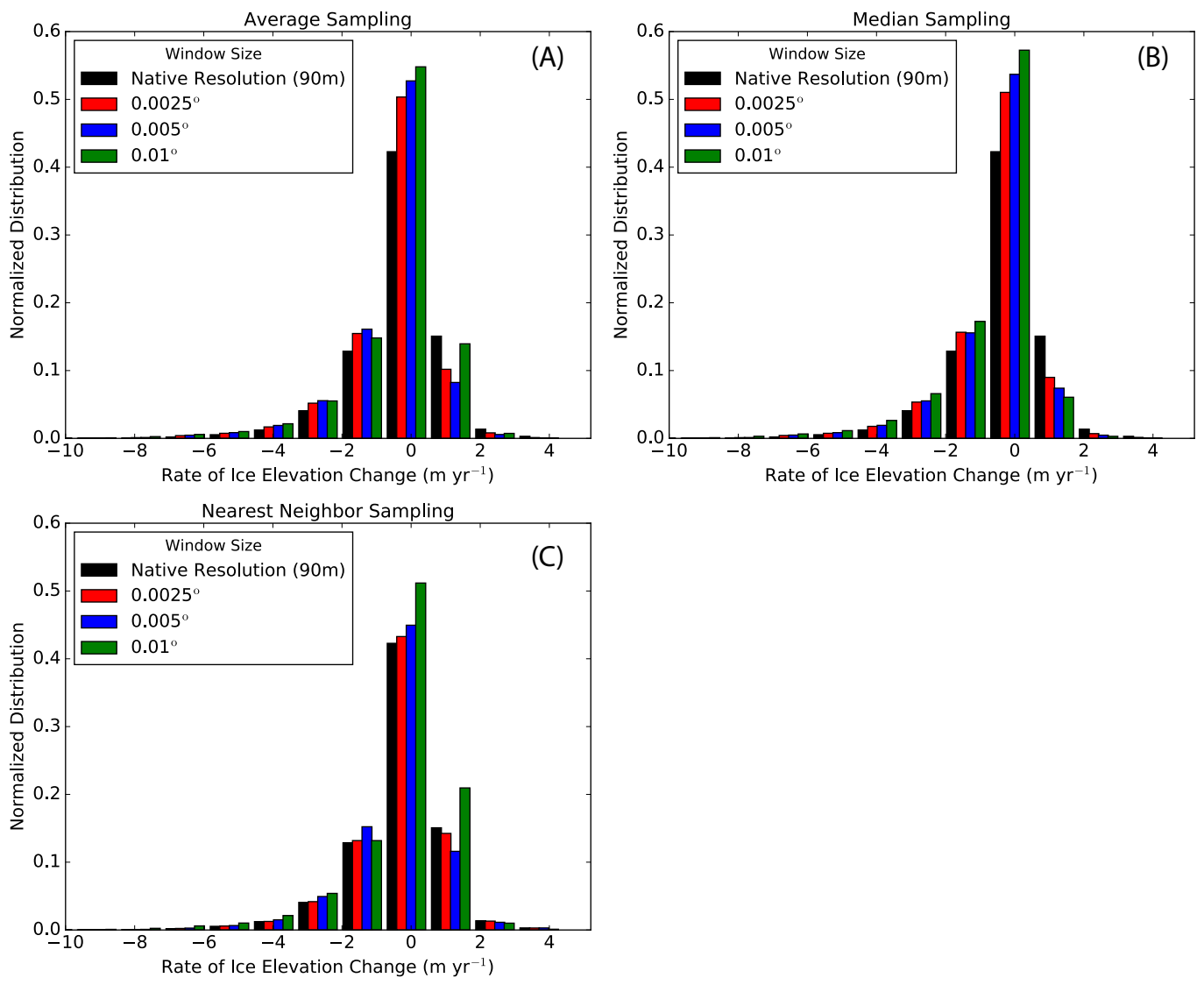

Figure 3. Histograms of $\frac{d h}{d t}$ sampled at $90 \mathrm{~m}, 0.0025^{\circ}, 0.005^{\circ}$, and $0.01^{\circ}$ resolutions under average (A), median (B), and nearest-neighbor (C) schemes. Median and averaging sampling methods show modest to no improvement in converging to the original $\frac{d h}{d t}$ distribution with increased resolution. Using the nearest neighbor method, $\frac{d h}{d t}$ distributions converge between sampling resolutions of $0.0025^{\circ}-0.005^{\circ}$. 
where $\mathrm{N}$ is 42 . The uncertainties arising from modeling a heterogeneous elastic structure with a $1 \mathrm{D}$ model $\left(\sigma_{\dot{\epsilon}}\right)$ are found similarly by stacking all elastic uplift rate maps calculated from the LITHO1.0 models and taking the standard deviation of the elastic uplift rates at each pixel.

\section{Results}

\subsection{Sensitivity to Elastic Structure with Depth}

We construct sensitivity kernels to constrain the depth of the elastic structure to which the uplift signal is most sensitive following Doin et al. [2015] and Zhao et al. [2016]. We divide the PREM elastic structure into $5 \mathrm{~km}$ thick segments. The Young's modulus of the uppermost segment is reduced by a factor of 2, keeping the Poisson's ratio constant, and elastic uplift rates modeled from the perturbed structure are subtracted from those modeled with the original PREM. This process is repeated, each time migrating the perturbed layer down by a depth of $2.5 \mathrm{~km}$ until a depth of $120 \mathrm{~km}$ is reached.

Figure 4 shows a series of sensitivity kernels along a $12 \mathrm{~km}$ transect near the Grand Plateau Glacier in the Glacier Bay region (Figure 1). At the beginning of the transect, closest to the Grand Plateau Glacier, the largest increase in uplift rates results from a reduction in elastic parameters at $5 \mathrm{~km}$ depth, probing increasingly deep sections with greater distance along the transect. We consider amplitudes of the sensitivity kernel that are less than $5 \%$ of the average GPS uncertainty $\left(0.13 \mathrm{~mm} \mathrm{yr}^{-1}\right)$ to be insignificant, and the deepest portion of the elastic structure probed along this transect by the ice unloading is $10 \mathrm{~km}$ depth at a distance of $5 \mathrm{~km}$ from the Grand Plateau Glacier. A 1D sampling of elastic structure sensitivity kernels is appropriate for this area because the Grand Plateau Glacier protrudes out slightly from the rest of the Glacier Bay region.. Elsewhere, the ice geometry is more spatially complex, such as in between neighboring valley glaciers (e.g., the Grand Plateau and Fairweather glaciers, Figure 4) and requires 2D information about the elastic structure sensitivity kernels. We calculate sensitivity kernels at $0.1^{\circ}$ postings for all off-ice areas in the study region and record the depth and amplitude of the peak difference from the unperturbed model. A portion of this is shown as an example in Figures 4B and 4C. Pixels with amplitudes less than the $0.13 \mathrm{~mm} \mathrm{yr}^{-1}$ threshold are removed, and the depth values are plotted against distance from the nearest icecovered area (Figure 5). Figure 5 shows the depth of the elastic structure to which mod- 

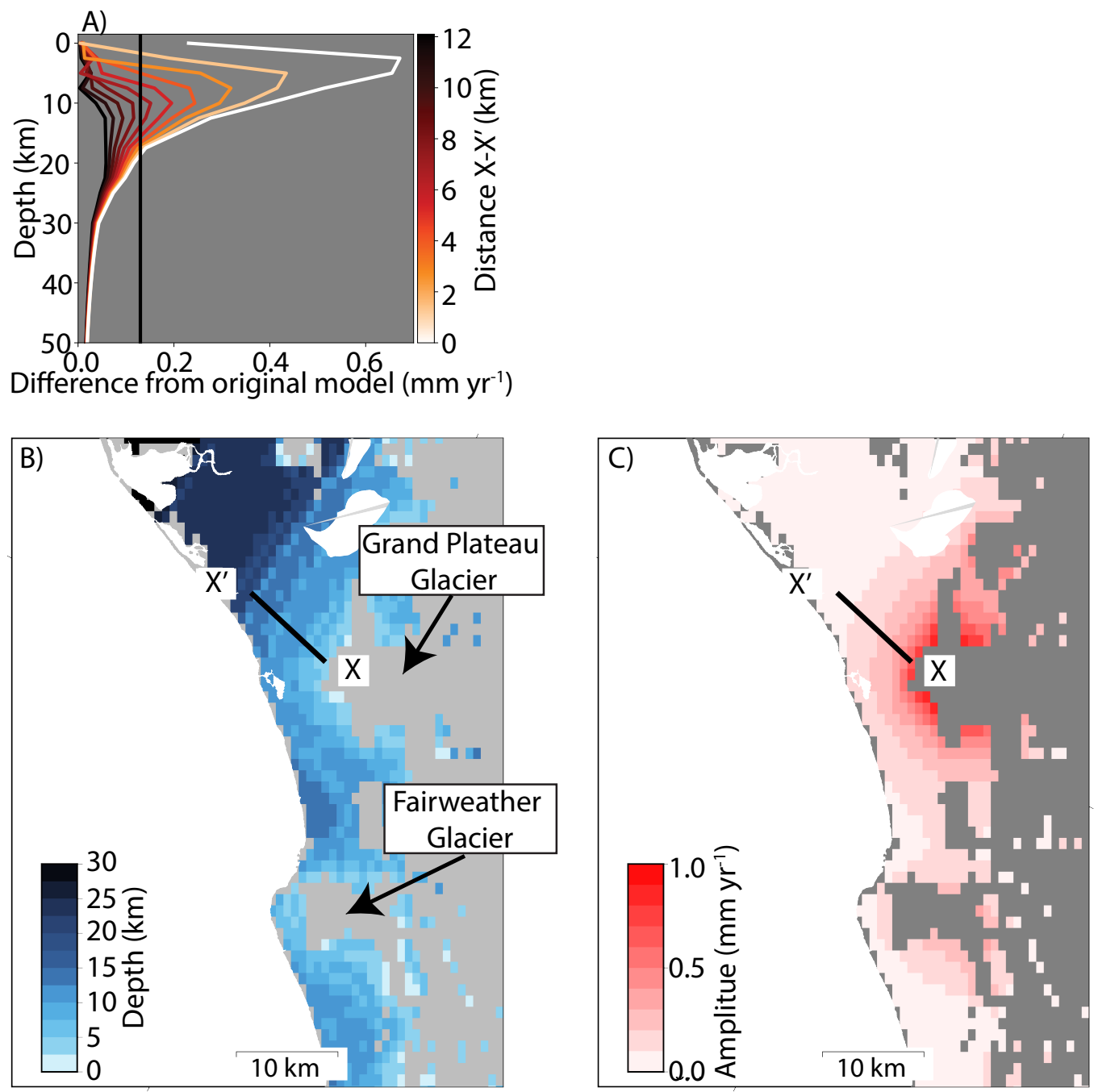

Figure 4. A) Depth sensitivity to perturbations from PREM. The Young's modulus of PREM is reduced by a factor of 2 for $5 \mathrm{~km}$ thick sublayers at various depths (y-axis), and elastic uplift rates modeled from the perturbed structures are subtracted from those modeled using the

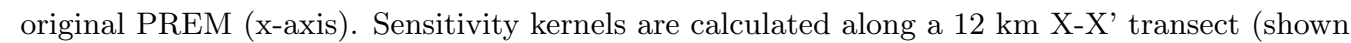
in panels B and C) with their distance along the transect shown by their color. Differences less than $5 \%$ of the average GPS uncertainty $\left(0.13 \mathrm{~mm} \mathrm{yr}^{-1}\right.$, black line $)$ are considered insignificant. Sensitivity kernels are calculated at $0.1^{\circ}$ postings for all off-ice areas in the study region, and the maximum difference and its associated depth are recorded. As an example, the depths and amplitudes of the peak differences are shown in panels B and C, respectively, for the region surrounding the Grand Plateau and Fairweather glaciers (see boxed region in Figure 1). 


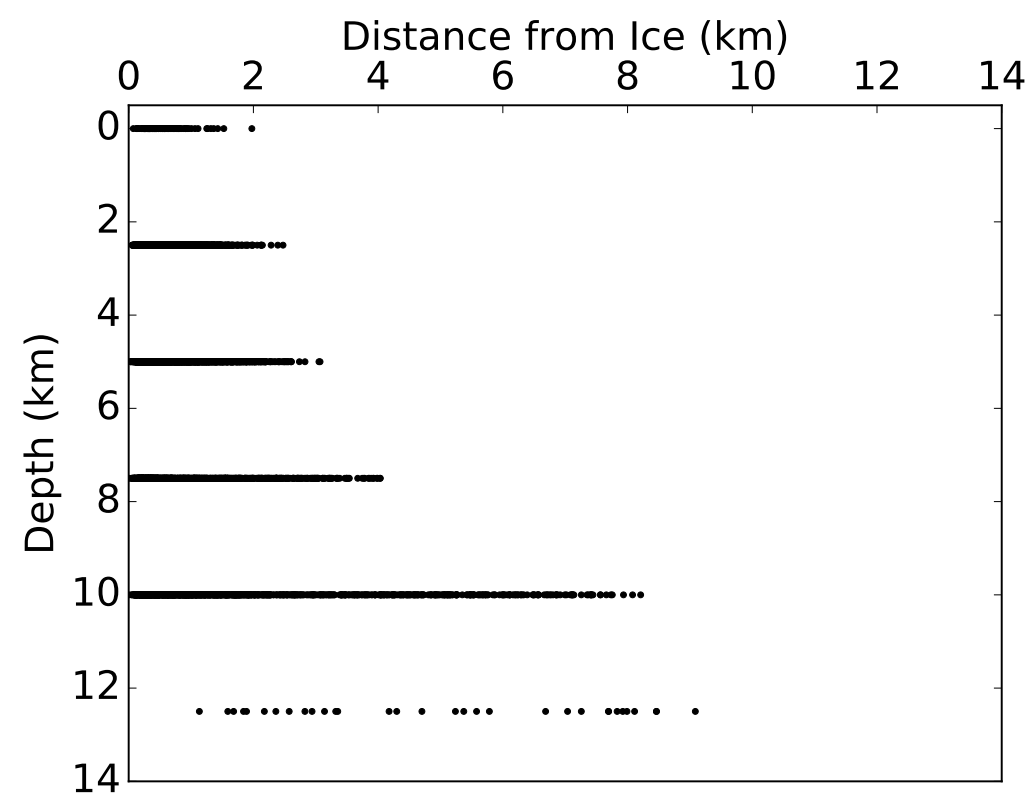

Figure 5. Depth of sensitivity to elastic structure (y axis) as a function of distance from the nearest ice-covered area. Pixels with a maximum difference less than $5 \%$ of the average GPS uncertainty $\left(0.13 \mathrm{~mm} \mathrm{yr}^{-1}\right)$ are omitted. Within $10 \mathrm{~km}$ distance from ice-covered areas, modeled elastic uplift rates are most sensitive to the upper $15 \mathrm{~km}$ of the elastic structure.

eled uplift rates are most sensitive does not extend beyond $15 \mathrm{~km}$ below the surface. Since all LITHO1.0 elastic structures extend to a depth of at least $40 \mathrm{~km}$, we are confident that all differences in elastic uplift rates are fully explored by our ensemble of elastic structures.

\subsection{Sensitivity to Crustal Elastic Structure}

Figure 6 shows the average of elastic uplift rates modeled for southeast Alaska using estimated $\frac{d h}{d t}$ (Figure 1) and the ensemble of LITHO1.0 elastic structure, as well as the locations of campaign GPS observations [Elliott et al., 2010] and contoured observed total uplift rates. Differences in elastic uplift rates modeled using PREM and the LITHO1.0 ensemble are most prominent in the near-field. To illustrate this, we plot these differences and elastic uplift rate uncertainty at every point in our study area against its distance from the nearest ice covered area (Figure 7). At $500 \mathrm{~m}$ from ice covered areas, or roughly two disc radii away from the center of the nearest load, the difference between $\dot{\epsilon}_{P R E M}$ and $\dot{\epsilon}_{L I T H O}$ is up to $2-4 \mathrm{~mm} \mathrm{yr}^{-1}$, or 1-2 times as large as the average uncer- 


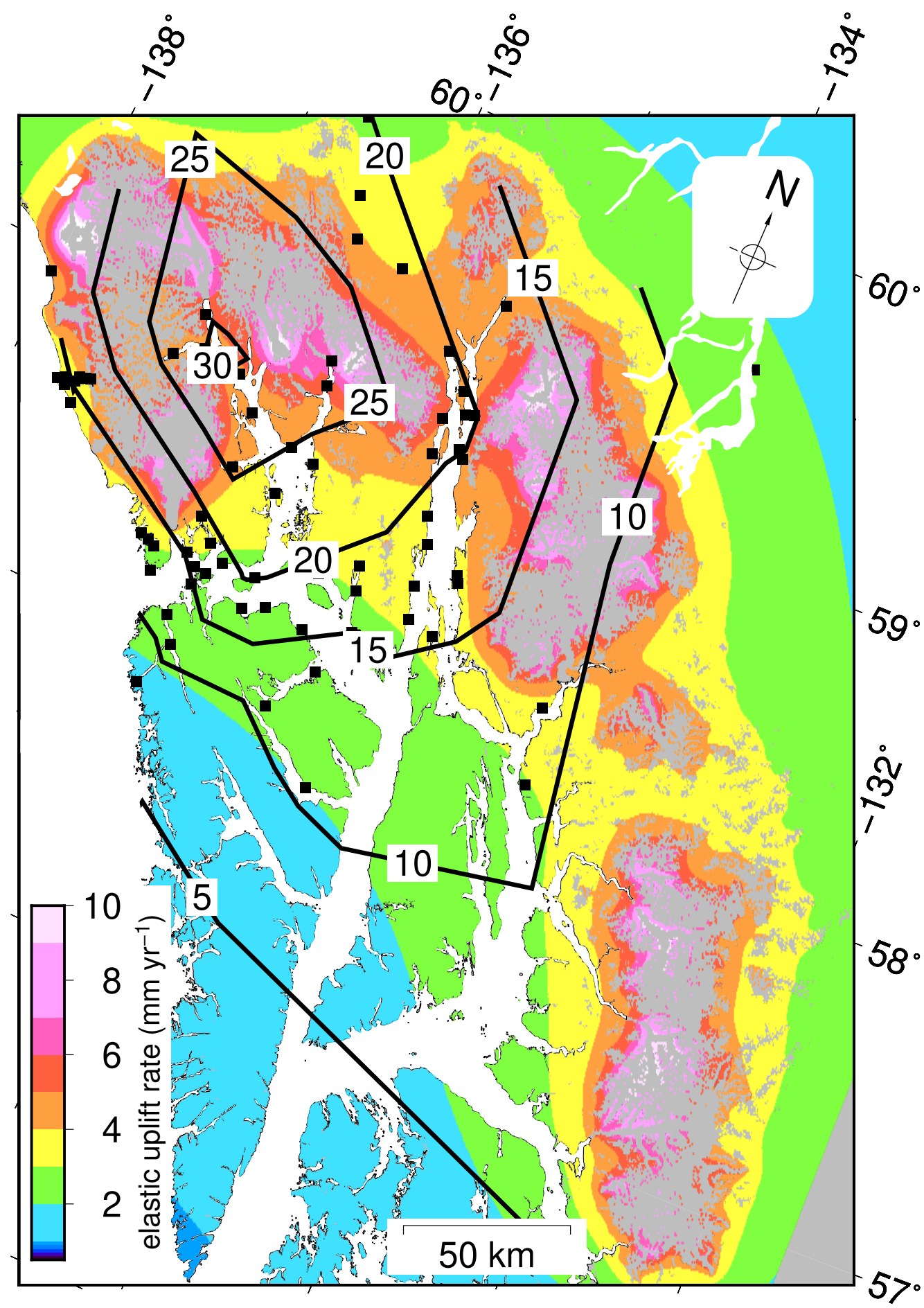

Figure 6. Average elastic uplift rates modeled using $\frac{d h}{d t}$ (Figure 1) and the ensemble of LITHO1.0 elastic structures (Figure 2) are shown in color. Differences between elastic uplift rates modeled using PREM and those modeled using the ensemble of LITHO1.0 elastic structures are minor at this scale. Black lines show contoured uplift rates observed with campaign GPS [Elliott et al., 2010]. 

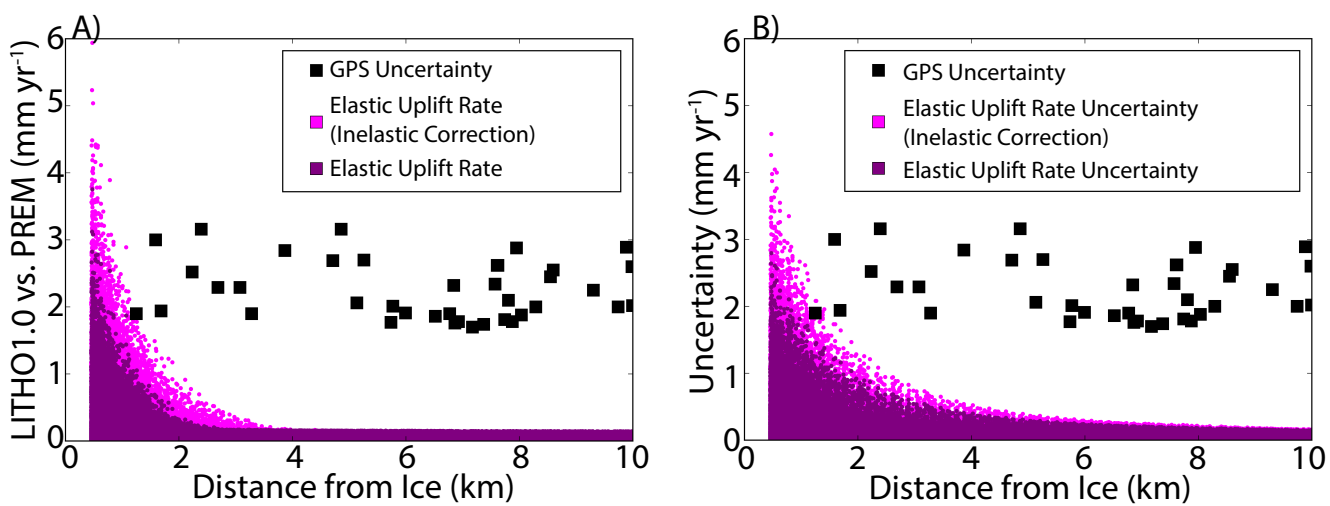

Figure 7. Scatter plots of all pixels of gridded elastic uplift rates plotted against distance to the nearest ice-covered area. A) Difference between elastic uplift rates modeled using the LITHO1.0 ensemble $\left(\dot{\epsilon}_{L I T H O}\right)$ and those modeled using PREM ( $\left.\dot{\epsilon}_{P R E M}\right)$. B) Uncertainty in elastic uplift rates due to lateral variations in crustal structure within the study region. The uncertainty of GPS observations are shown as black dots against distance from ice-covered areas. The lighter magenta color shows the impact of inelastic behavior in the crust on plots (A) and (B) found using Eq. 1.

tainty in the campaign GPS (Figure 7A). These differences decay quickly with distance from the ice. At $1 \mathrm{~km}$ away from the ice, differences between $\dot{\epsilon}_{P R E M}$ and $\dot{\epsilon}_{L I T H O}$ are $50 \%$ of the average GPS uncertainty ( $97 \%$ considering inelasticity) and become less than $10 \%$ at $\sim 3.5 \mathrm{~km}$ away. The uncertainties of $\dot{\epsilon}_{\text {LITHO }}$ that result from lateral variations in the elastic structure (Figure 7B) show similar results. The uncertainties decay more slowly with distance from the ice and are $50 \%$ of the GPS uncertainty by $1.3 \mathrm{~km}(2.2 \mathrm{~km}$ with inelasticity), becoming less than $10 \%$ by $5 \mathrm{~km}$. In southeast Alaska, the vast majority of GPS observations were made beyond this distance and the choice of crustal elastic structure does not have significant impact on the GIA deformation inferred. Using the PREM model, elastic uplift rates account for $18.8 \%$ of the total observed uplift, whereas this is $19.0 \pm 0.4 \%$ if the LITHO1.0 elastic structures are used and $18.8 \pm 0.5 \%$ after correcting for inelasticity.

Studies of glacial density or mass balance typically make use of geodetic observations close to the glacier of interest, as this is where the elastic deformation is greatest [e.g., Bevan et al., 2015]. To explore the sensitivity of these studies to the choice of crustal elastic structure, we consider only local differences from the global average elastic struc- 


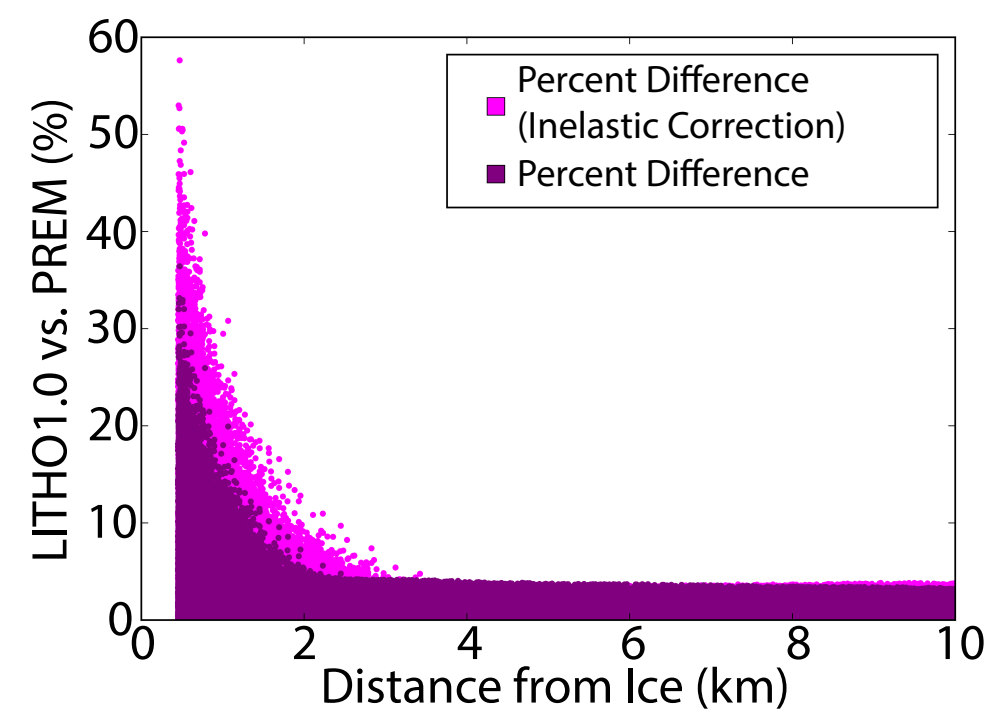

Figure 8. Scatter plot showing the percentage difference between elastic uplift rates modeled with local elastic structures and those modeled with PREM against distance from the nearest ice covered area. The lighter magenta color shows the impact of inelastic behavior in the crust found using Eq. 1.

ture, rather than lateral variations in elastic structure within the study region. Figure 8 shows the average increase in elastic uplift rates when modeled using local LITHO 1.0 elastic structure compared to elastic uplift rates modeled using PREM. Differences at $500 \mathrm{~m}$ from the ice peak at $\sim 20 \%$ difference from $\dot{\epsilon}_{P R E M}$ (dark color in Figure 8). When inelasticity is considered, this peaks at $\sim 40 \%$.

\section{Discussion}

\subsection{Impact on Glacial Density and Mass Balance}

Many studies that use GPS or InSAR uplift observations to investigate dynamic glacier processes or glacier mass balance record the largest elastic uplift signal by taking measurements close to the edge of the glacier [e.g., Liu et al., 2012; Nielsen et al., 2013; Bevan et al., 2015; Adhikari et al., 2017]. This is also where the modeled elastic uplift rates are most sensitive to the local crustal elastic structure (Figures 4, 7). Elastic uplift rates modeled with local crustal elastic structures are different from those modeled with PREM by up to $\sim 20 \%$ at the fastest thinning glaciers, and as much as $40 \%$ if the effects of inelasticity are considered. This uncertainty range is pertinent to stud- 
ies that use elastic uplift observations with volumetric constraints to estimate the density of glacier material lost or gained [e.g., Bevan et al., 2015], as the difference between the densities of firn $\left(\sim 550 \mathrm{~kg} \mathrm{~m}^{-3}\right)$ and ice $\left(900 \mathrm{~kg} \mathrm{~m}^{-3}\right)$ is comparable to the uncertainty range found here, particularly if inelasticity is considered.

In two studies of seasonal elastic deformation of Iceland, Drouin et al. [2016] and Compton et al. [2017] found that in order to match the known seasonal mass changes of the ice caps, it is necessary to scale the Green's functions of PREM by a factor of $\sim 2 \times$. This difference is comparable to the 20-40\% difference between $\dot{\epsilon}_{L I T H O}$ and $\dot{\epsilon}_{P R E M}$ found in this study (Figure 8), however the differences seen here are significant only to $<1 \mathrm{~km}$ from ice covered areas. While some of the GPS observations used by Compton et al. [2017], are less than $1 \mathrm{~km}$ distance from the ice caps, most are greater than $10 \mathrm{~km}$ away. In Iceland, icecaps seasonally gain and lose $\sim 1.5-2.5 \mathrm{~m}$ w.e., representing much larger mass changes than the annual unloading in southeast Alaska of $\sim 0.75 \mathrm{~m}$ w.e. $\mathrm{yr}^{-1}$ (Figure 1). The larger mass changes in Iceland seen seasonally could increase the distance from ice covered areas to which deformation significantly depends on the site-specific elastic structure. While we find in this study that the elastic structure of the crust is important to consider for observations made $<1 \mathrm{~km}$ from ice covered areas, this distance threshold only applies to southeast Alaska under the current annual mass loss rates. We recommend future investigations consider this distance sensitivity in other regions.

\subsubsection{Inelasticity}

In this study, we account for the effects of inelasticity in the upper crust using the empirical relations between the static-dynamic ratios of Young's moduli fit by Yale et al. [2017] using and ensemble of triaxial strain experiments. In the absence of first principle methods for modeling inelasticity, these are a good first approximation. They suggest that the differences between the dynamic behavior of the crust at the time scales of seismic wave propagation compared to the static behavior at longer time scales could introduce significant bias and uncertainty in models of elastic deformation to cryospheric loads. The stress, strain, temperature conditions, and lithologies used in the experiments considered by Yale et al. [2017] were designed to model the conditions of hydrocarbon reservoirs, and further experiments are needed to test how applicable these results are to a broader array of environmental conditions. The workflow presented in this study could be used to identify which areas are expected to have the greatest sensitivity to in- 
elastic processes so that geodetic observations could be placed to optimize such experiments.

\subsection{Impact on Inferred Glacial Isostatic Adjustment}

In southeast Alaska, the majority of current GPS observations are located $5 \mathrm{~km}$ or more away from ice covered areas. At these locations, the difference in modeled elastic uplift rates induced by modifying the crustal structure is insignificant compared to the campaign GPS uncertainty and does not affect interpretations of GIA deformation in the region made by previous studies (Larsen et al., 2005, Elliot et al., 2010; Sato et al., 2011). Based on these findings we expect that in studies of other regions of rapid regional GIA (e.g., Iceland [Auriac et al., 2013], Patagonia [Lange et al., 2014], and regions of West Antarctica [Nield et al., 2014; Barletta et al., 2018]) most of the geodetic observations will be similarly unaffected. However, among these areas are a few measurements where elastic uplift accounts for $\geq 30 \%$ of the observed uplift rates (e.g., near the head of Viedma and Upsala glaciers in the Southern Patagonian Icefield [Lange et al., 2014], Foyn Point in the Northern Antarctic Peninsula [Nield et al., 2014], and near the Backer Islands in the Amundsen Sea Embayment [Barletta et al., 2018]) and it is possible that these observations may be significantly impacted by their site-specific crustal structure.

We have also incrementally updated previous southeast Alaska GIA studies by estimating the elastic deformation using ice mass balance estimated from satellite imagery that is roughly coterminous with the GPS acquisition time period. Using the updated ice mass balance estimates, we find that the percentage of total observed uplift rates described by elastic deformation in southeast Alaska is $\sim 19 \%$, lower than the $\sim 26 \%$ found by Sato et al. [2011], and in closer agreement with the $\sim 20 \%$ found by Larsen et al. [2005]. Using a two layer Earth model, Sato et al. [2011] found that increased elastic deformation rates (and therefore lower inferred viscous deformation rates), resulted in estimates of asthenospheric viscosity of $5.6_{-1.6}^{+6.4} \times 10^{18} \mathrm{~Pa} \mathrm{~s}$, roughly $1.5 \times$ higher than the $3.7_{-0.7}^{+0.3} \times 10^{18} \mathrm{~Pa} \mathrm{~s}$ found by Larsen et al. [2005]. The better agreement between the percentage of total observed uplift rates described by elastic deformation between this study and Larsen et al. [2005] supports their lower estimates of asthenospheric viscosity.

We propose two main reasons why we find lower elastic uplift rates on average than Sato et al. [2011] despite using more recent, and in many places higher, ice thinning rates. 
The first is due to the methods used for downsampling maps of ice thinning rates in preparation for modeling elastic deformation. In previous studies of GIA in southeast Alaska, ice thinning rates were downsampled using averaging windows of $0.18^{\circ}$ [Larsen et al., 2005; Elliott et al., 2010], and $0.083^{\circ} \times 0.042^{\circ}$ [Sato et al., 2011]. When ice thinning rates of this study are downsampled by averaging at $0.01^{\circ}$ resolution, the $\frac{d h}{d t}$ distribution becomes too narrowly centered around its mode, resulting in an overly-negative mass balance (Figure 3). Similar results are found when using median and nearest neighbor sampling methods at this resolution (Figure 3). Using $\frac{d h}{d t}$ sampled at this resolution results in biased elastic uplift rates (Figure 7 of the supplementary material), and downsampling with an average sampling approach at lower resolutions likely biased the ice thinning rate distributions of the previous studies. When sampling the $\frac{d h}{d t}$ with the nearest neighbor method at $0.005^{\circ}$ and $0.0025^{\circ}$ resolutions, the elastic deformation estimates converge at a lower value. The second reason why we found elastic deformation comprises a smaller percentage of the total observed uplift in comparison to Sato et al. [2011] is due to differences in ice mass balance estimates. The ice mass balance estimates used by Sato et al. [2011] to model elastic deformation were based on an elevation time series in which the latest elevations were from the radar-based SRTM DEM. Because the SRTM DEM is a C-band radar product, it penetrates into the snow, firn, and ice, mapping out an elevation below the surface. Previously, this penetration depth had been under-corrected [Berthier et al., 2018], resulting in overly-negative ice mass balance estimates from time series ending in the SRTM DEM. In this study, this penetration depth is corrected using the 'linear extrapolation' method (Supplementary Section 1.1; Berthier et al., 2016; Wang and Kaab, 2015). Ice thinning rates estimated from a combination of the SRTM and elevation data based on optical imagery agree well with our estimates of $\frac{d h}{d t}$ based solely on optical imagery (Figure 3 of the supplementary material), as well as with ice mass balance estimates from previous studies based on independent datasets [Johnson et al., 2013].

\section{Conclusions}

We quantify the uncertainties in modeled elastic uplift response of the solid Earth to deglaciation between the years 2000-2017 in southeast Alaska. Using an ensemble of site-specific 1D elastic structures, we account for differences between the properties of our study region and that of the global average (i.e., PREM), the effects of modeling a 
laterally variable region using $1 \mathrm{D}$ elastic structures, and the inelastic behavior of the upper crust. Uncertainties associated with the choice of elastic structure dominate the elastic uplift rate uncertainty at locations close to ice covered areas (i.e., less than $\sim 1 \mathrm{~km}$ distance), where they can be 1-2x larger than the average campaign GPS uncertainty. Indeed, close to ice covered areas, elastic uplift rates modeled using local elastic structures can have differences of up to $20-40 \%$ to those modeled using PREM. This has the potential to introduce large biases into glaciological studies that use observations of elastic uplift observations close to ice covered areas, and we recommend that future studies use caution in considering the choice of elastic structure. These uncertainties are largely attenuated at distances greater than $1 \mathrm{~km}$ from ice covered areas. The vast majority of GPS observations in this region of southeast Alaska were made past this distance threshold, where elastic uplift rate uncertainties are small in comparison, and do not affect interpretations of GIA deformation made by previous studies. Differences in load changes could alter the distance from ice covered areas to which deformation significantly depends on the site-specific elastic structure, and the $1 \mathrm{~km}$ distance threshold found in this study applies only to southeast Alaska. We recommend further investigation into the impact of elastic uplift rate uncertainties in other deglaciating regions.

\section{Acknowledgments}

We thank the editor Paul Tregoning, Erik Ivins, and two anonymous reviewers for their constructive suggestions and review. This work was funded by a NASA Earth and Space Science Fellowship. ASTER data were provided by the Land Processes Distributed Active Archive Center, part of the NASA Earth Observing System Data and Information System (EOSDIS) at the USGS Earth Resources Observation and Science (EROS) Center in Sioux Falls, SD, USA and is available at https://lpdaac.usgs.gov/dataset_discovery/aster/aster_products_ta ArcticDEM data were provided by the Polar Geospatial Center under NSF OPP awards 1043681, 1559691 and 1542736 and may be acquired at https://www.pgc.umn.edu/data/arcticdem/ The SRTM DEM was provided by NASA (https://www2.jpl.nasa.gov/srtm/). The package giapy used to calculate load Love numbers is available from https://github.com/skachuck/giapy. The package REAR [Melini et al., 2015] used to calculate Green's functions and convolve disc loads is available from http://hpc.rm.ingv.it/rear. Estimated ice elevation change rates and modeled elastic uplift rates used in this study are available at https://figshare.com/s/d064f3d2e867b621 


\section{References}

Adhikari, S., E. R. Ivins, and E. Larour (2017), Mass transport waves amplified by intense Greenland melt and detected in solid Earth deformation, Geophysical Research Letters, 44(10), 4965-4975, doi:10.1002/2017GL073478.

Ameen, M. S., B. G. Smart, J. M. Somerville, S. Hammilton, and N. A. Naji (2009), Predicting rock mechanical properties of carbonates from wireline logs (a case study: Arab-d reservoir, ghawar field, saudi arabia), Marine and Petroleum Geology, 26(4), 430-444.

Arendt, A. A., K. A. Echelmeyer, W. D. Harrison, C. S. Lingle, and V. B. Valentine (2002), Rapid Wastage of Alaska Glaciers and Their Contribution to Rising Sea Level, 382(2002), doi:10.1126/science.1072497.

Asef, M. R., and A. R. Najibi (2013), The effect of confining pressure on elastic wave velocities and dynamic to static Young's modulus ratio, Geophysics, 78(3), D135-D142.

Auriac, a., K. H. Spaans, F. Sigmundsson, a. Hooper, P. Schmidt, and B. Lund (2013), Iceland rising: Solid Earth response to ice retreat inferred from satellite radar interferometry and visocelastic modeling, Journal of Geophysical Research: Solid Earth, 118(4), 1331-1344, doi:10.1002/jgrb.50082.

Barletta, V. R., M. Bevis, B. E. Smith, T. Wilson, A. Brown, A. Bordoni, M. Willis, S. A. Khan, M. Rovira-Navarro, I. Dalziel, et al. (2018), Observed rapid bedrock uplift in amundsen sea embayment promotes ice-sheet stability, Science, $360(6395), 1335-1339$

Berthier, E., V. Cabot, C. Vincent, and D. Six (2016), Decadal Region-Wide and Glacier-Wide Mass Balances Derived from Multi-Temporal ASTER Satellite Digital Elevation Models. Validation over the Mont-Blanc Area, Frontiers in Earth Science, 4(June), 1-16, doi:10.3389/feart.2016.00063.

Berthier, E., C. Larsen, W. J. Durkin, M. J. Willis, and M. E. Pritchard (2018), Brief communication: Unabated wastage of the Juneau and Stikine icefields (southeast Alaska) in the early 21st century, The Cryosphere, 12(4), 1523-1530, doi:10.5194/tc-12-1523-2018.

Bevan, S. L., A. Luckman, S. a. Khan, and T. Murray (2015), Seasonal dynamic thinning at Helheim Glacier, Earth and Planetary Science Letters, 415, 47-53, doi:10.1016/j.epsl.2015.01.031. 
Bevis, M., D. Melini, and G. Spada (2016), On computing the geoelastic response to a disk load, Geophysical Journal International, 205(3), 1804-1812.

Brantut, N., M. Heap, P. Meredith, and P. Baud (2013), Time-dependent cracking and brittle creep in crustal rocks: A review, Journal of Structural Geology, 52, $17-43$.

Carcione, J. M., F. Poletto, and B. Farina (2018), The burgers/squirt-flow seismic model of the crust and mantle, Physics of the Earth and Planetary Interiors, 274, $14-22$.

Cathles, L. M. (1975), Viscosity of the Earth's Mantle, vol. 1362, Princeton University Press.

Cheng, C., and D. H. Johnston (1981), Dynamic and static moduli, Geophysical Research Letters, 8(1), 39-42.

Compton, K., R. A. Bennett, and S. Hreinsdóttir (2015), Climate-driven vertical acceleration of icelandic crust measured by continuous gps geodesy, Geophysical Research Letters, 42(3), 743-750.

Compton, K., R. A. Bennett, S. Hreinsdóttir, T. van Dam, A. Bordoni, V. Barletta, and G. Spada (2017), Short-term variations of Icelandic ice cap mass inferred from cGPS coordinate time series, Geochemistry, Geophysics, Geosystems, 18(6), 2099-2119, doi:10.1002/2017GC006831.

Dehecq, A., R. Millan, E. Berthier, N. Gourmelen, E. Trouvé, and V. Vionnet (2016), Elevation changes inferred from TanDEM-X data over the Mont-Blanc area: Impact of the X-band interferometric bias, IEEE Journal of Selected Topics in Applied Earth Observations and Remote Sensing, 9(8), 3870-3882.

Dill, R., V. Klemann, Z. Martinec, and M. Tesauro (2015), Applying local Green's functions to study the influence of the crustal structure on hydrological loading displacements, Journal of Geodynamics, 88, 14-22, doi:10.1016/j.jog.2015.04.005.

Doin, M. P., C. Twardzik, G. Ducret, C. Lasserre, S. Guillaso, and S. Jianbao (2015), InSAR measurement of the deformation around Siling Co Lake: Inferences on the lower crust viscosity in central Tibet, Journal of Geophysical Research B: Solid Earth, 120(7), 5290-5310, doi:10.1002/2014JB011768.

Drouin, V., K. Heki, F. Sigmundsson, S. Hreinsdóttir, and B. G. Ófeigsson (2016), Constraints on seasonal load variations and regional rigidity from continuous GPS measurements in Iceland, 1997-2014, Geophysical Journal International, 205(3), 
1843-1858, doi:10.1093/gji/ggw122.

Dziewonski, A. M., and D. L. Anderson (1981), Preliminary reference earth model, Physics of the earth and planetary interiors, 25(4), 297-356.

Elliott, J. L., C. F. Larsen, J. T. Freymueller, and R. J. Motyka (2010), Tectonic block motion and glacial isostatic adjustment in southeast Alaska and adjacent Canada constrained by GPS measurements, Journal of Geophysical Research: Solid Earth, 115(9), 1-21, doi:10.1029/2009JB007139.

Farrell, W. (1972), Deformation of the Earth by surface loads, Reviews of Geophysics, 10(3), 761-797.

Gardelle, J., E. Berthier, and Y. Arnaud (2012), Slight mass gain of Karakoram glaciers in the early twenty-first century Slight mass gain of Karakoram glaciers in the early twenty-first century, Nature Geoscience, 5(5), 1-4, doi:10.1038/ngeo1450.

Gardner, A. S., G. Moholdt, J. G. Cogley, B. Wouters, A. A. Arendt, J. Wahr, E. Berthier, R. Hock, W. T. Pfeffer, G. Kaser, et al. (2013), A reconciled estimate of glacier contributions to sea level rise: 2003 to 2009, science, 340(6134), $852-857$.

Huss, M. (2013), Density assumptions for converting geodetic glacier volume change to mass change, The Cryosphere, $7(3), 877-887$.

Jeans, J. H. (1923), The propagation of earthquake waves, Proc. R. Soc. Lond. A, 102(718), 554-574.

Johnson, A. J., C. F. Larsen, N. Murphy, A. A. Arendt, and S. Lee Zirnheld (2013), Mass balance in the Glacier Bay area of Alaska, USA, and British Columbia, Canada, 1995-2011, using airborne laser altimetry, Journal of Glaciology, 59(216), 632-648, doi:10.3189/2013JoG12J101.

Johnson, P., and P. Rasolofosaon (1996), Manifestation of nonlinear elasticity in rock: convincing evidence over large frequency and strain intervals from laboratory studies, Nonlinear processes in geophysics, 3(2), 77-88.

Kachuck, S. (2018), Time-domain glacial isostatic adjustment: theory, computation, and statistical applications, Ph.D. thesis, Cornell University.

Khan, S. A., J. Wahr, L. A. Stearns, G. S. Hamilton, T. van Dam, K. M. Larson, and O. Francis (2007), Elastic uplift in southeast greenland due to rapid ice mass loss, Geophysical Research Letters, $34(21)$. 
King, M. S. (1983), Static and dynamic elastic properties of igneous and metamorphic rocks from the canadian shield.

Lange, H., G. Casassa, E. R. Ivins, L. Schröder, M. Fritsche, A. Richter, A. Groh, and R. Dietrich (2014), Observed crustal uplift near the Southern Patagonian Icefield constrains improved viscoelastic Earth models, pp. 805-812, doi: 10.1002/2013GL058419.determined.

Larsen, C. F., R. J. Motyka, J. T. Freymueller, K. A. Echelmeyer, and E. R. Ivins (2005), Rapid viscoelastic uplift in southeast Alaska caused by post-Little Ice Age glacial retreat, Earth and Planetary Science Letters, 237(3-4), 548-560, doi: 10.1016/j.epsl.2005.06.032.

Larsen, C. F., R. J. Motyka, A. A. Arendt, K. a. Echelmeyer, and P. E. Geissler (2007), Glacier changes in southeast Alaska and northwest British Columbia and contribution to sea level rise, Journal of Geophysical Research: Earth Surface, 112(1), 1-11, doi:10.1029/2006JF000586.

Larsen, C. F., E. Burgess, A. A. Arendt, S. O’Neel, A. J. Johnson, and C. Kienholz (2015), Surface melt dominates Alaska glacier mass balance, Geophysical Research Letters, 42(14), 5902-5908, doi:10.1002/2015GL064349.

Liu, L., J. Wahr, I. Howat, S. A. Khan, I. Joughin, and M. Furuya (2012), Constraining ice mass loss from Jakobshavn Isbræ (Greenland) using InSARmeasured crustal uplift, Geophysical Journal International, 188(3), 994-1006, doi:10.1111/j.1365-246X.2011.05317.x.

Luthcke, S. B., T. Sabaka, B. Loomis, A. Arendt, J. McCarthy, and J. Camp (2013), Antarctica, greenland and gulf of alaska land-ice evolution from an iterated grace global mascon solution, Journal of Glaciology, 59(216), 613-631.

Melini, D., P. Gegout, O. Midi-Pyrenees, and G. Spada (2015), a regional elastic rebound calculator.

Melkonian, A. K., M. J. Willis, M. E. Pritchard, a. Rivera, F. Bown, and S. A. Bernstein (2014), Satellite-derived volume loss rates and glacier speeds for the Cordillera Darwin Icefield, Chile, Cryosphere, 7(3), 823-839, doi:10.5194/tc-7-8232013.

Melkonian, A. K., M. J. Willis, and M. E. Pritchard (2016), Stikine Icefield Mass Loss between 2000 and 2013/2014, Frontiers in Earth Science, 4(October), doi: 10.3389/feart.2016.00089. 
Moratto, Z., M. Broxton, R. Beyer, M. Lundy, and K. Husmann (2010), Ames Stereo Pipeline, NASA's open source automated stereogrammetry software, in Lunar and Planetary Science Conference, vol. 41, p. 2364.

Najibi, A. R., M. Ghafoori, G. R. Lashkaripour, and M. R. Asef (2015), Empirical relations between strength and static and dynamic elastic properties of asmari and sarvak limestones, two main oil reservoirs in iran, Journal of Petroleum Science and Engineering, 126, 78-82.

Nield, G. A., V. R. Barletta, A. Bordoni, M. A. King, P. L. Whitehouse, P. J. Clarke, E. Domack, T. A. Scambos, and E. Berthier (2014), Rapid bedrock uplift in the Antarctic Peninsula explained by viscoelastic response to recent ice unloading, Earth and Planetary Science Letters, 397, 32-41, doi: 10.1016/j.epsl.2014.04.019

Nield, G. A., P. L. Whitehouse, M. A. King, and P. J. Clarke (2016), Glacial isostatic adjustment in response to changing late holocene behaviour of ice streams on the siple coast, west antarctica, Geophysical Supplements to the Monthly Notices of the Royal Astronomical Society, 205(1), 1-21.

Nielsen, K., S. A. Khan, G. Spada, J. Wahr, M. Bevis, L. Liu, and T. van Dam (2013), Vertical and horizontal surface displacements near jakobshavn isbræ driven by melt-induced and dynamic ice loss, Journal of Geophysical Research: Solid Earth, 118(4), 1837-1844.

Noh, M. J., and I. M. Howat (2015), Automated stereo-photogrammetric DEM generation at high latitudes: Surface Extraction with TIN-based Search-space Minimization (SETSM) validation and demonstration over glaciated regions, GIScience and Remote Sensing, 52(2), 198-217, doi:10.1080/15481603.2015.1008621.

Nuimura, T., K. Fujita, S. Yamaguchi, and R. R. Sharma (2012), Elevation changes of glaciers revealed by multitemporal digital elevation models calibrated by GPS survey in the Khumbu region, Nepal Himalaya, 1992-2008, Journal of Glaciology, $58(210), 648-656$.

Pan, E., J. Chen, M. Bevis, A. Bordoni, V. R. Barletta, and A. Molavi Tabrizi (2015), An analytical solution for the elastic response to surface loads imposed on a layered, transversely isotropic and self-gravitating earth, Geophysical Supplements to the Monthly Notices of the Royal Astronomical Society, 203(3), 21502181. 
Pasyanos, M. E., T. G. Masters, G. Laske, and Z. Ma (2014), LITHO1.0: An updated crust and lithospheric model of the Earth, Journal of Geophysical Research: Solid Earth, 119(3), 2153-2173.

Pfeffer, W. T., A. A. Arendt, A. Bliss, T. Bolch, J. G. Cogley, A. S. Gardner, J.-O. Hagen, R. Hock, G. Kaser, C. Kienholz, et al. (2014), The Randolph Glacier Inventory: a globally complete inventory of glaciers, Journal of Glaciology, 60(221), $537-552$.

Ramage, J. M., B. L. Isacks, and M. M. Miller (2000), Radar glacier zones in southeast Alaska, U.S.A.: Field and satellite observations, Journal of Glaciology, 46(153), 287-296, doi:10.3189/172756500781832828.

Sato, T., C. F. Larsen, S. Miura, Y. Ohta, H. Fujimoto, W. Sun, R. J. Motyka, and J. T. Freymueller (2011), Reevaluation of the viscoelastic and elastic responses to the past and present-day ice changes in Southeast Alaska, Tectonophysics, 511(3-4), 79-88, doi:10.1016/j.tecto.2010.05.009.

Sauber, J. M., and B. F. Molnia (2004), Glacier ice mass fluctuations and fault instability in tectonically active southern alaska, Global and Planetary Change, 42(1-4), 279-293.

Sella, G. F., S. Stein, T. H. Dixon, M. Craymer, T. S. James, S. Mazzotti, and R. K. Dokka (2007), Observation of glacial isostatic adjustment in "stable" North America with GPS, Geophysical Research Letters, 34(2), 1-6, doi: 10.1029/2006GL027081.

Shepherd, A., E. Ivins, E. Rignot, B. Smith, M. van den Broeke, I. Velicogna, P. Whitehouse, K. Briggs, I. Joughin, G. Krinner, et al. (2018), Mass balance of the Antarctic Ice Sheet from 1992 to 2017, Nature, 558(7709), 219-222, doi: 10.1038/s41586-018-0179-y.

Smith, L. C., R. R. Forster, B. L. Isacks, and D. K. Hall (1997), Seasonal climatic forcing of alpine glaciers revealed with orbital synthetic aperture radar, Journal of Glaciology, 43(145), 480-488, doi:10.1017/S0022143000035085.

Spaans, K., S. Hreinsdóttir, A. Hooper, and B. G. Ófeigsson (2015), Crustal movements due to Iceland's shrinking ice caps mimic magma inflow signal at Katla volcano, Nature Publishing Group, (December 2014), 1-8, doi:10.1038/srep10285.

Steffen, H., and P. Wu (2011), Glacial isostatic adjustment in fennoscandiaa review of data and modeling, Journal of geodynamics, 52(3-4), 169-204. 
Tesauro, M., P. Audet, M. K. Kaban, R. Bürgmann, and S. Cloetingh (2012), The effective elastic thickness of the continental lithosphere: Comparison between rheological and inverse approaches, Geochemistry, Geophysics, Geosystems, 13(9).

Tutuncu, A. N., A. L. Podio, A. R. Gregory, and M. M. Sharma (1998), Nonlinear viscoelastic behavior of sedimentary rocks, part i: Effect of frequency and strain amplitude, Geophysics, 63(1), 184-194.

Wahr, J., S. A. Khan, T. Dam, L. Liu, J. H. Angelen, M. R. Broeke, and C. M. Meertens (2013), The use of gps horizontals for loading studies, with applications to northern california and southeast greenland, Journal of Geophysical Research: Solid Earth, 118(4), 1795-1806.

Wang, D., and A. Kääb (2015), Modeling Glacier Elevation Change from DEM Time Series, Remote Sensing, 7(8), 10,117-10,142, doi:10.3390/rs70810117.

Willis, M. J., A. K. Melkonian, M. E. Pritchard, and A. Rivera (2012), Ice loss from the Southern Patagonian Ice Field, South America, between 2000 and 2012, Geophysical research letters, 39(17).

Wong, T.-f., and P. Baud (2012), The brittle-ductile transition in porous rock: A review, Journal of Structural Geology, 44, 25-53.

Yale, D., V. Swami, et al. (2017), Conversion of Dynamic Mechanical Property Calculations to Static Values for Geomechanical Modeling, in 51st US Rock Mechanics/Geomechanics Symposium, American Rock Mechanics Association.

Zhao, W., F. Amelung, T. H. Dixon, S. Wdowinski, and R. Malservisi (2014), A method for estimating ice mass loss from relative InSAR observations: Application to the Vatnajökull ice cap, Iceland, Geochemistry, Geophysics, Geosystems, 15(1), 108-120, doi:10.1002/2013GC004936.

Zhao, W., F. Amelung, M. P. Doin, T. H. Dixon, S. Wdowinski, and G. Lin (2016), InSAR observations of lake loading at Yangzhuoyong Lake, Tibet: Constraints on crustal elasticity, Earth and Planetary Science Letters, 449, 240-245, doi: 10.1016/j.epsl.2016.05.044. 


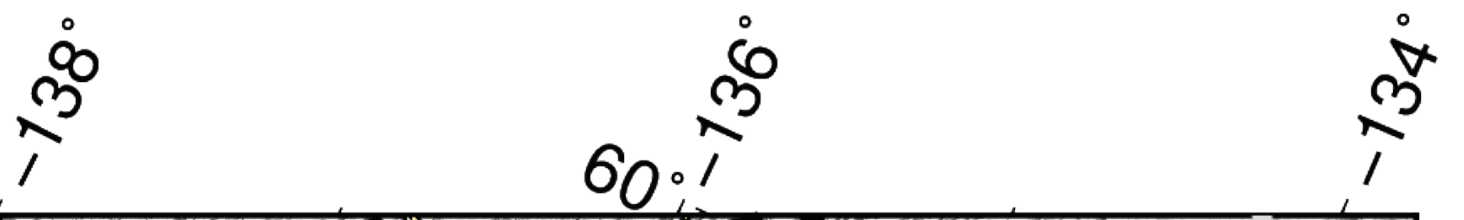

\section{作} (n)

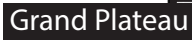
(n) 17 .

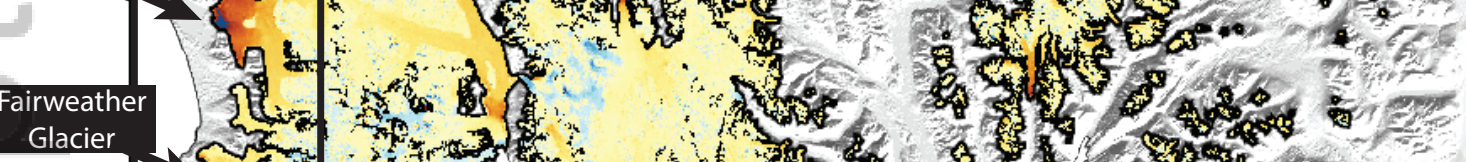

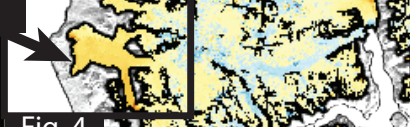

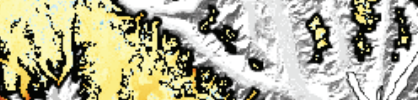

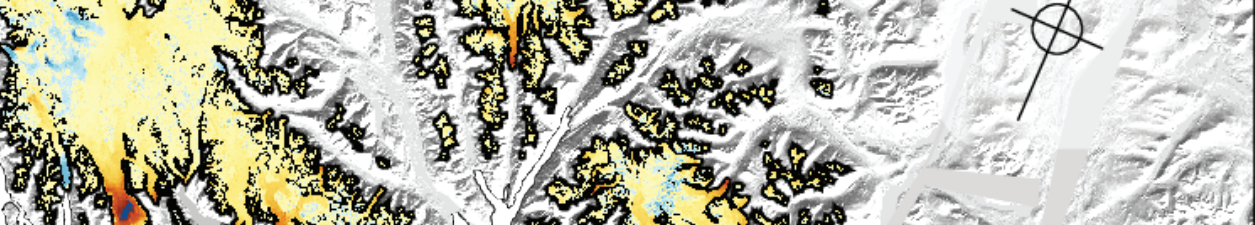
Ne. $60^{\circ}$

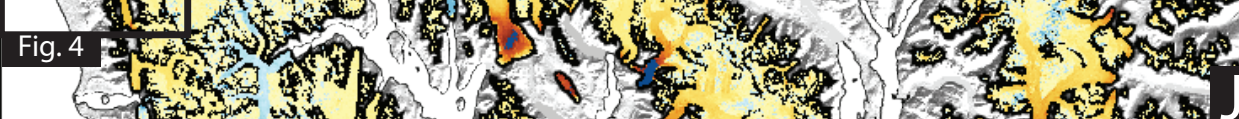

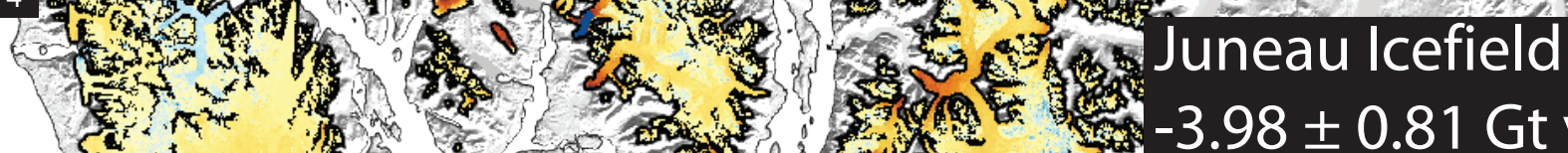

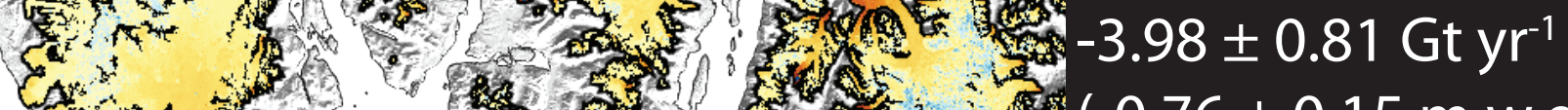
(4.

\section{Glacier Bay}

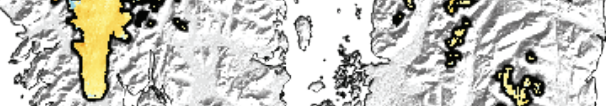

$-5.26 \pm 0.79 \mathrm{Gt} \mathrm{yr}^{-1}$ $\left(-0.76 \pm 0.11 \mathrm{~m}^{2}\right.$ w.e. $\left.\mathrm{yr}^{-1}\right)$ 的

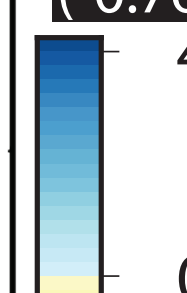

4

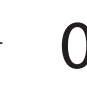

$0 \tau$ -

文

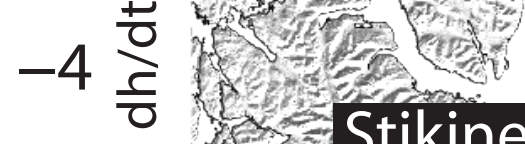

口. . Stikine lcefield ot yr ${ }^{-1}$

$-8$ s.e. A.
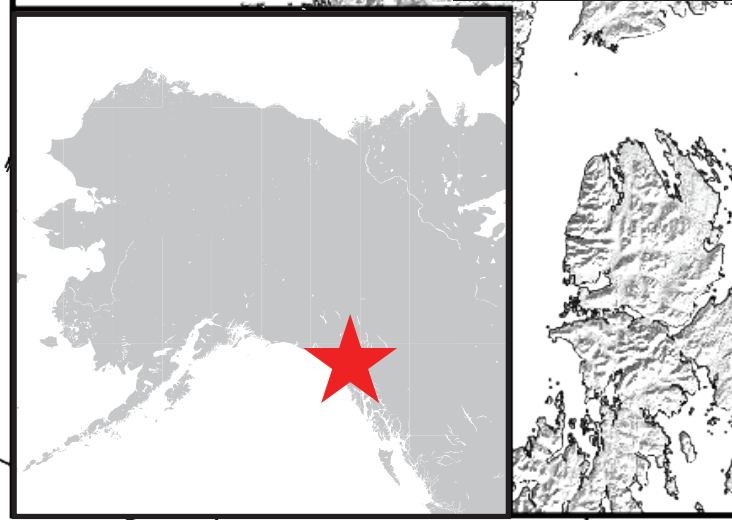
$0.08 \mathrm{~m}$ w.e.

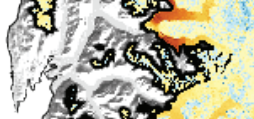

s 0

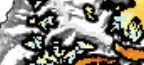

(a)

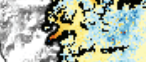

然

(i)
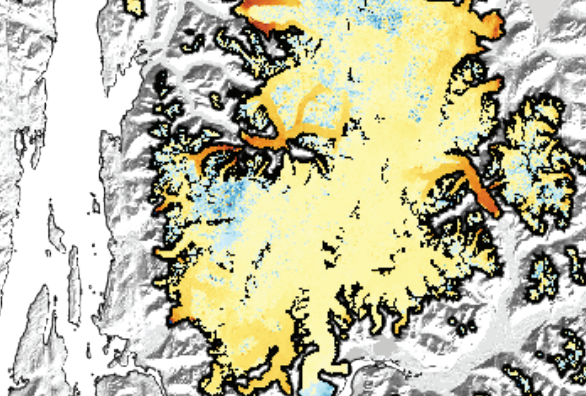

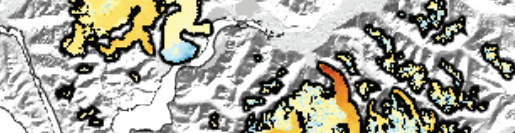

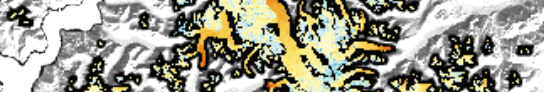

Obfor w o

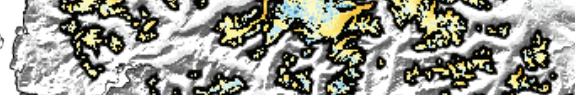

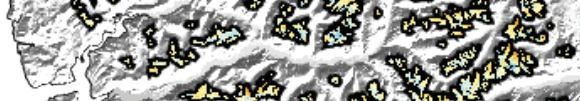

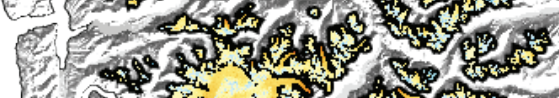

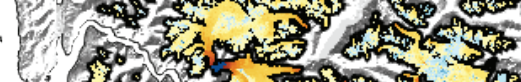

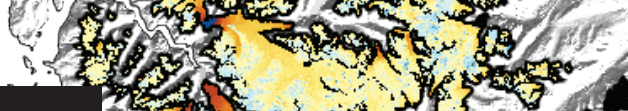

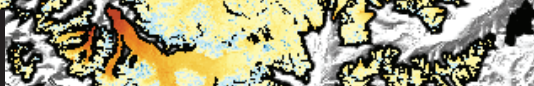
4 ticis and

as

$\left.y r^{-1}\right)$

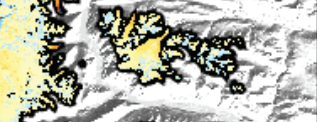

$58^{\circ}$

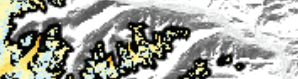

istis

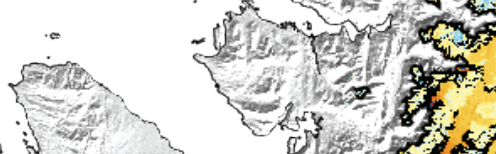

ing $\frac{10}{30}, 15$ Lof

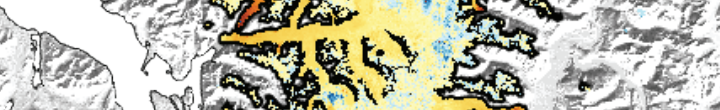
$192 v+5$ 1362 . nit. 49 is 2616

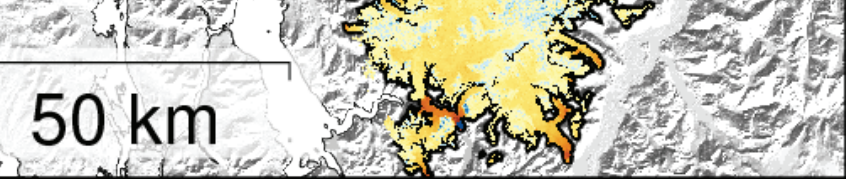

$59^{\circ}$

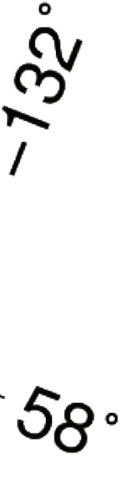




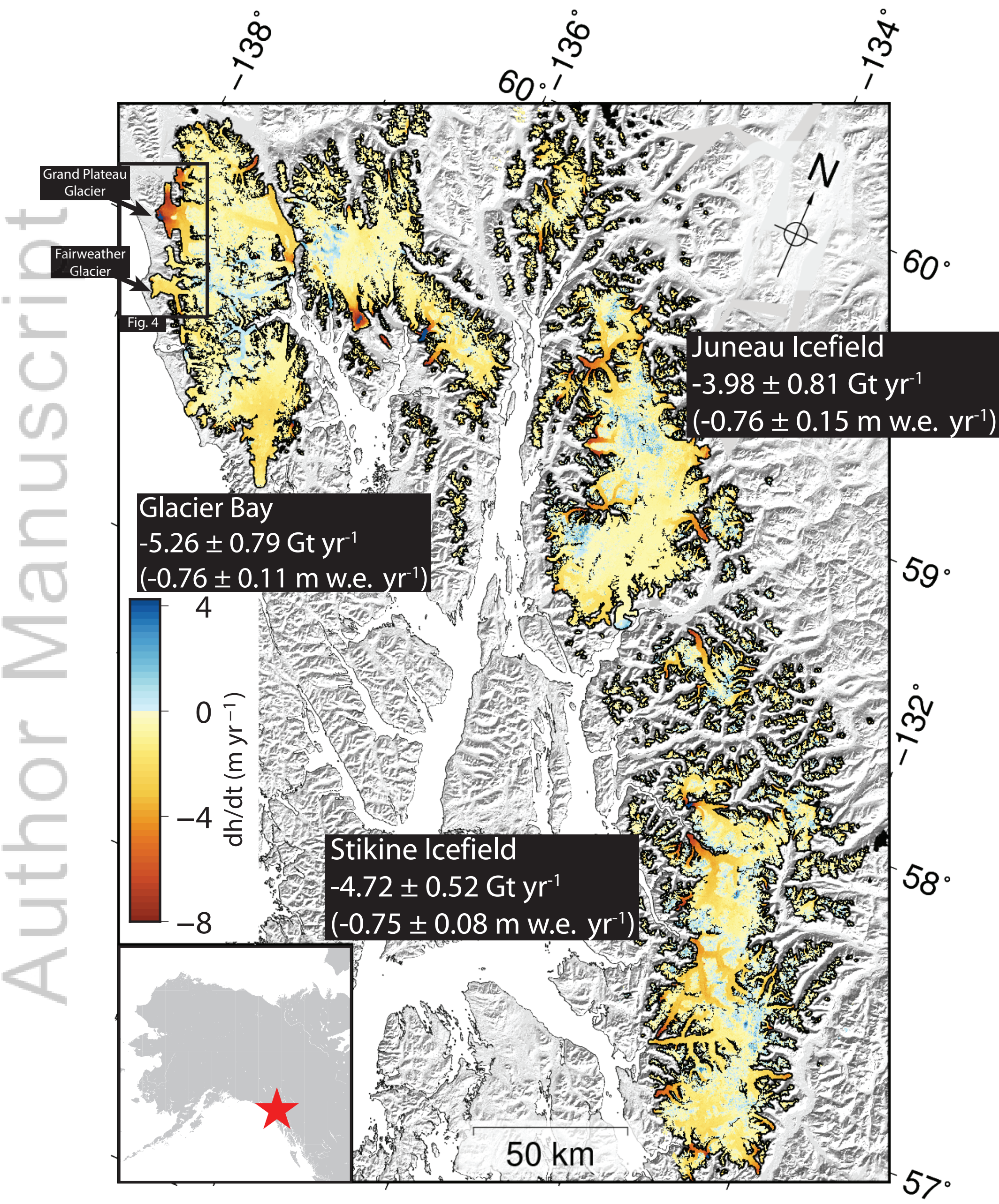




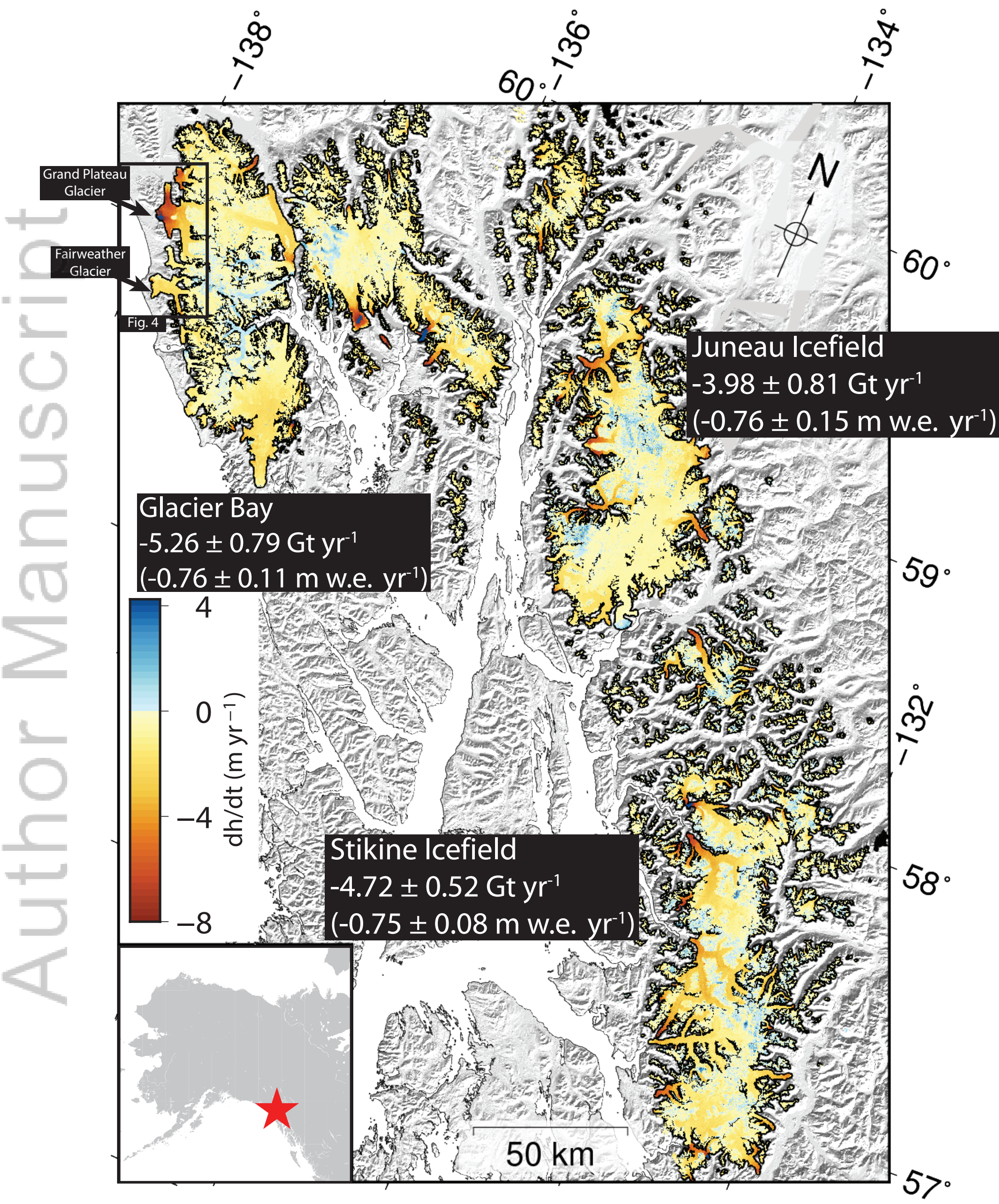




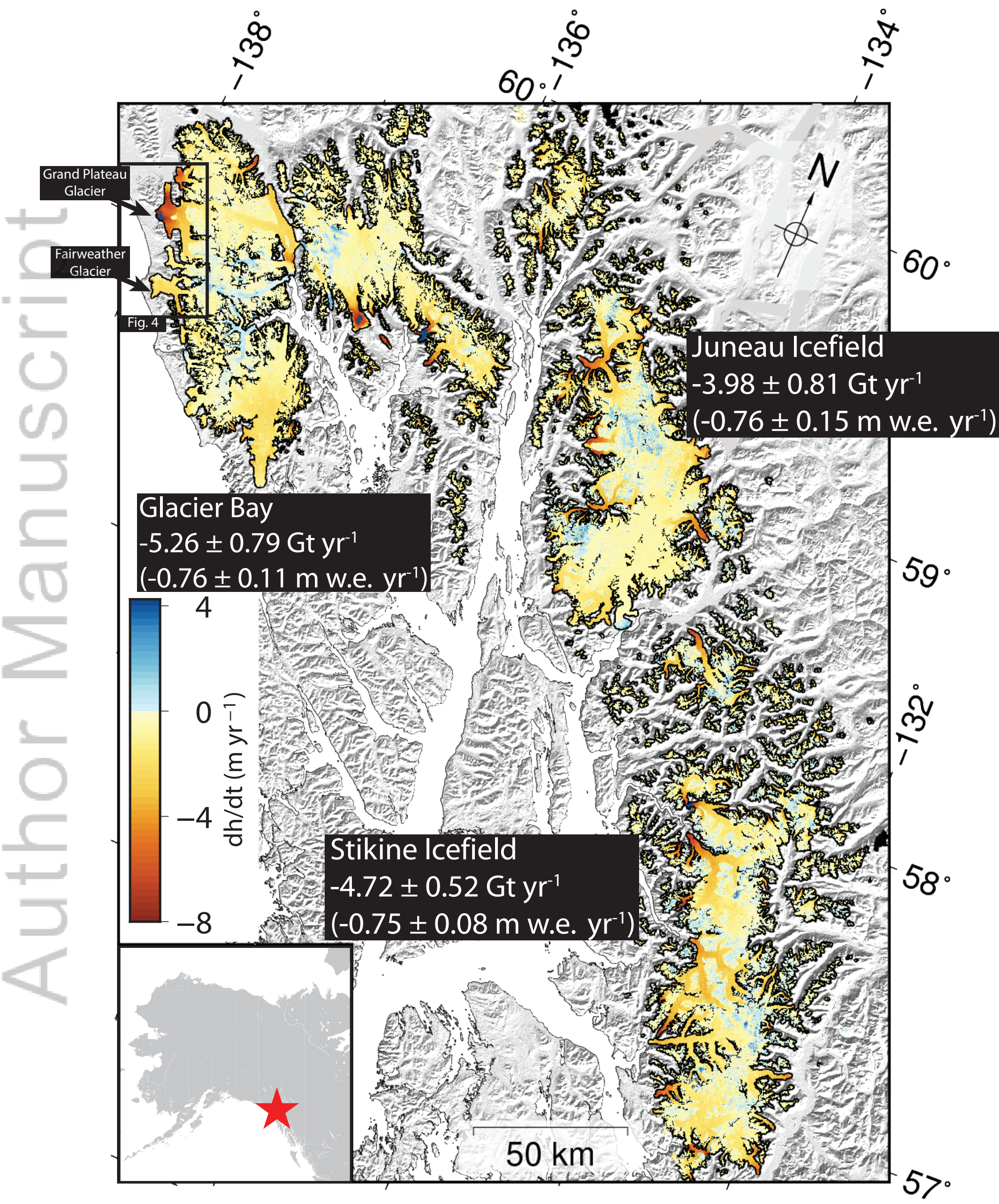




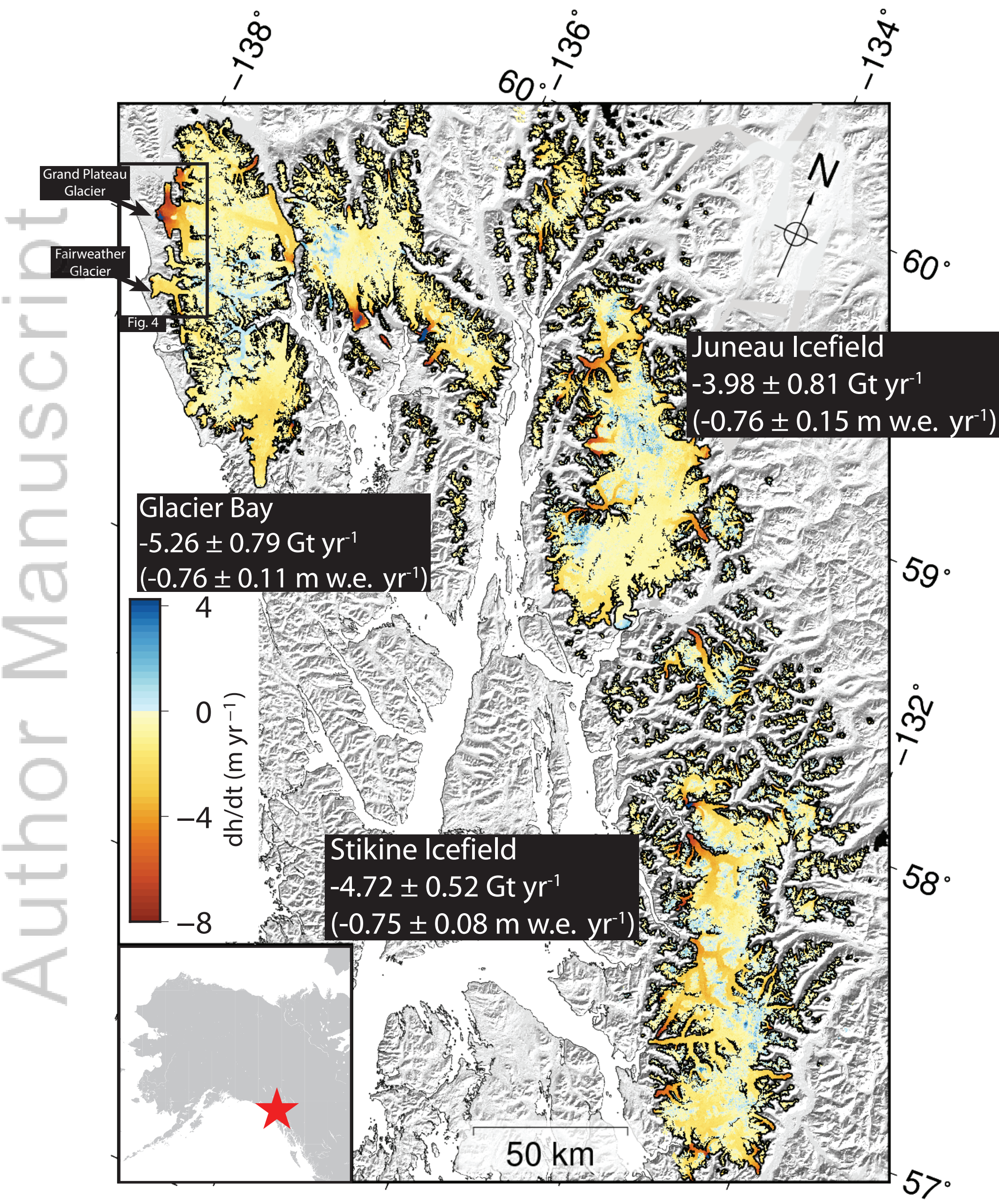


Figure 2.
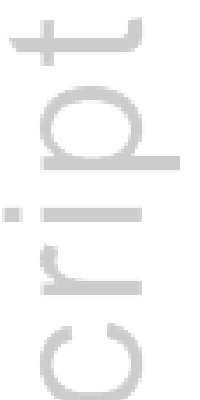

$\infty$
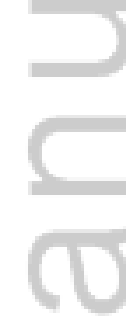

This article is protected by copyright. All rights reserved. 


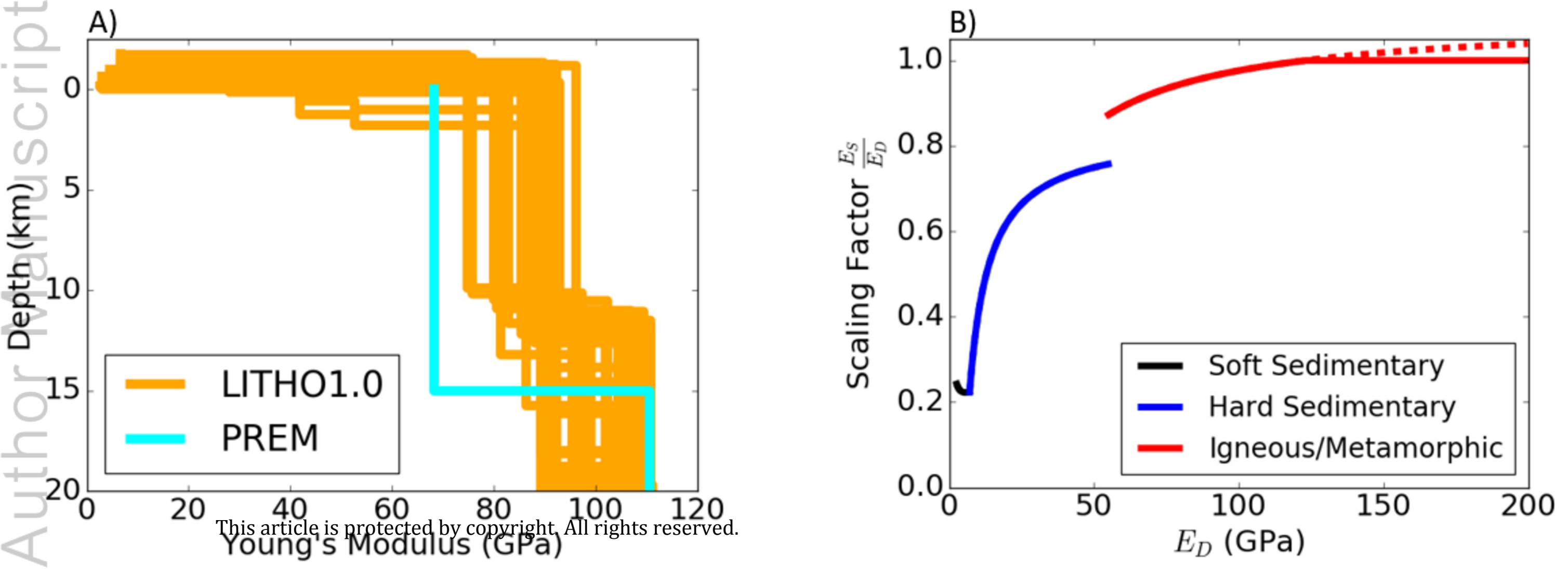


Figure 5.
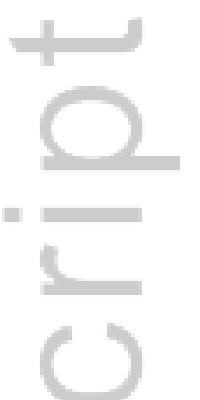

$\infty$
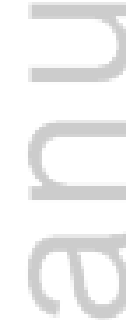

This article is protected by copyright. All rights reserved. 


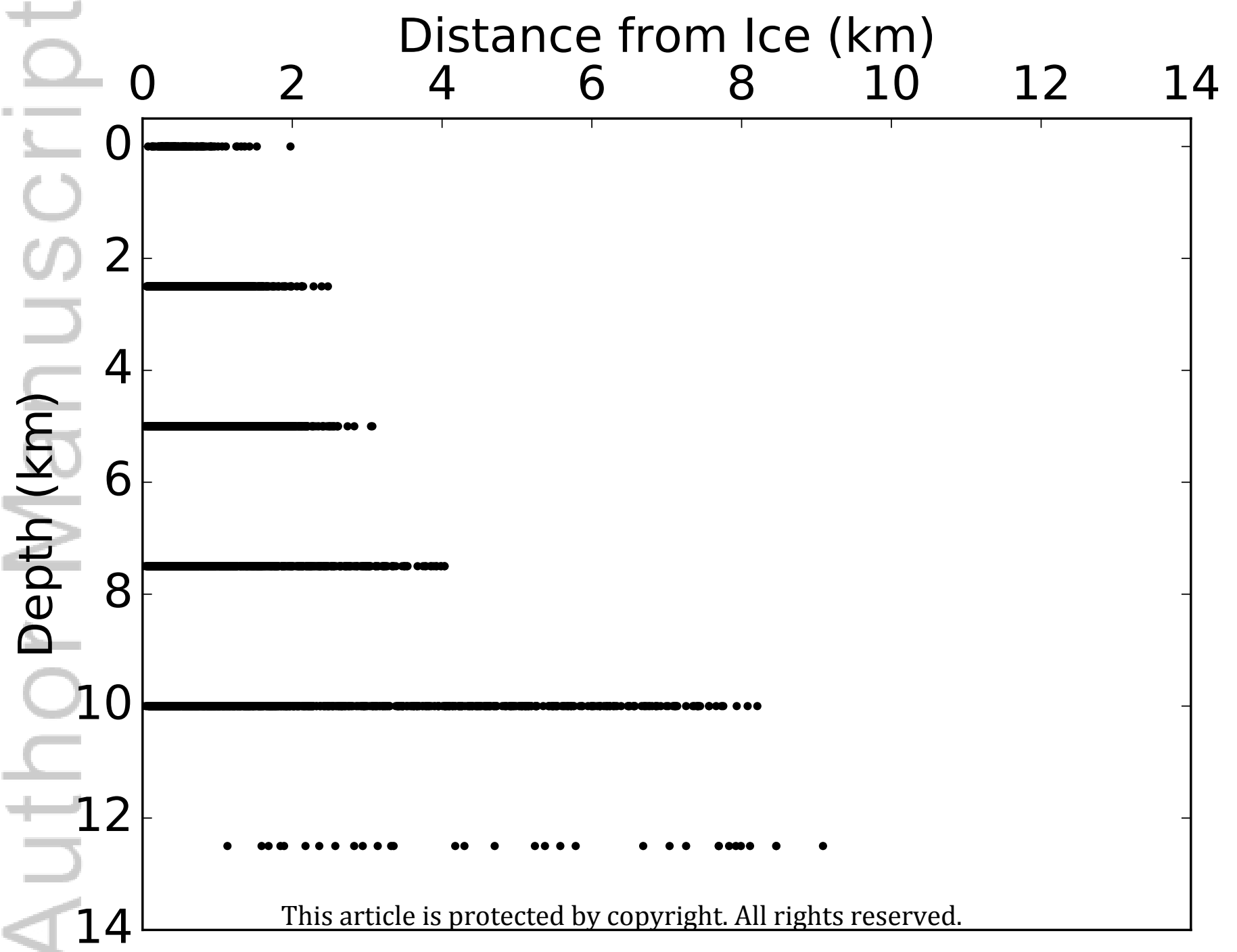




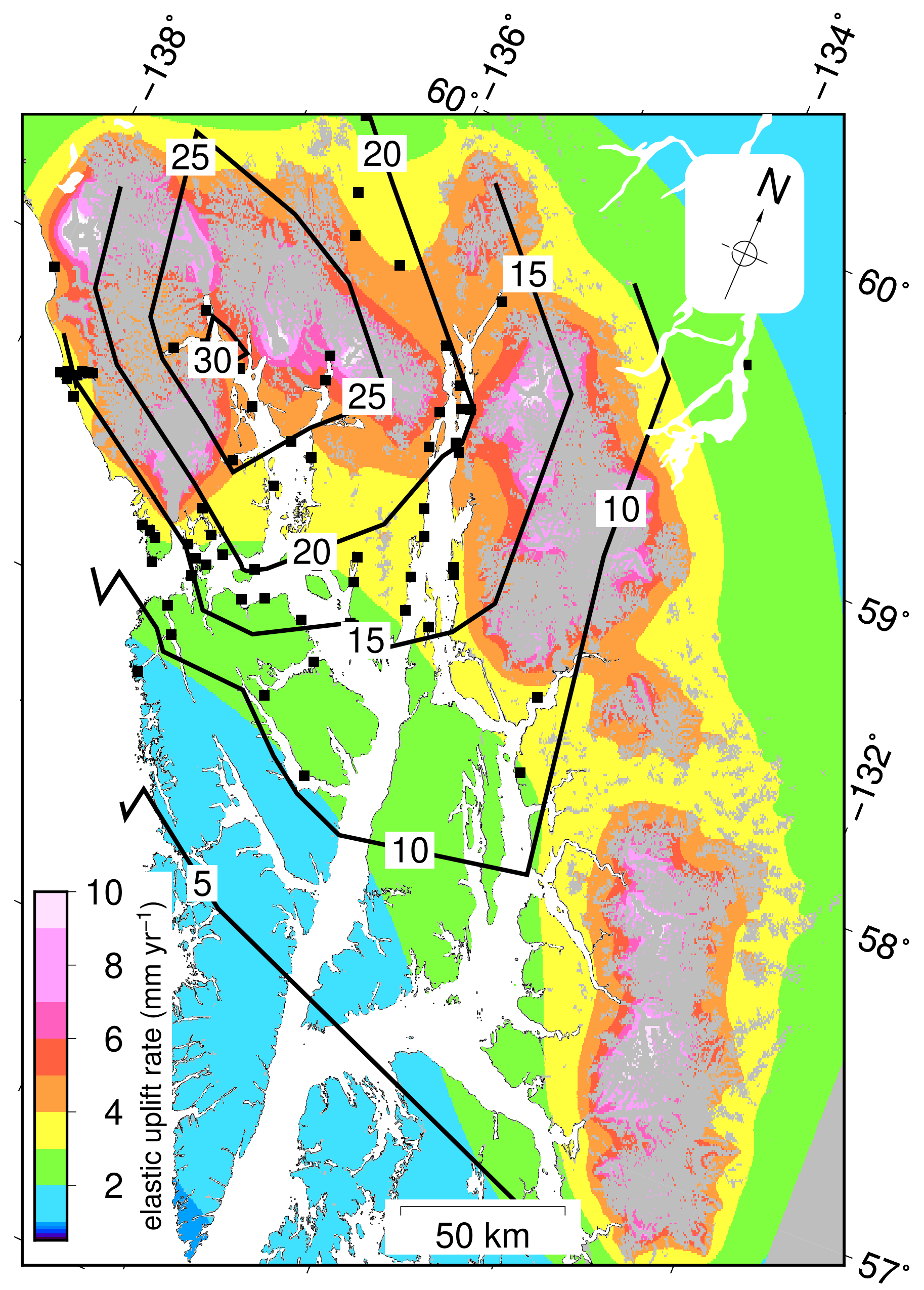

This article is protected by copyright. All rights reserved. 


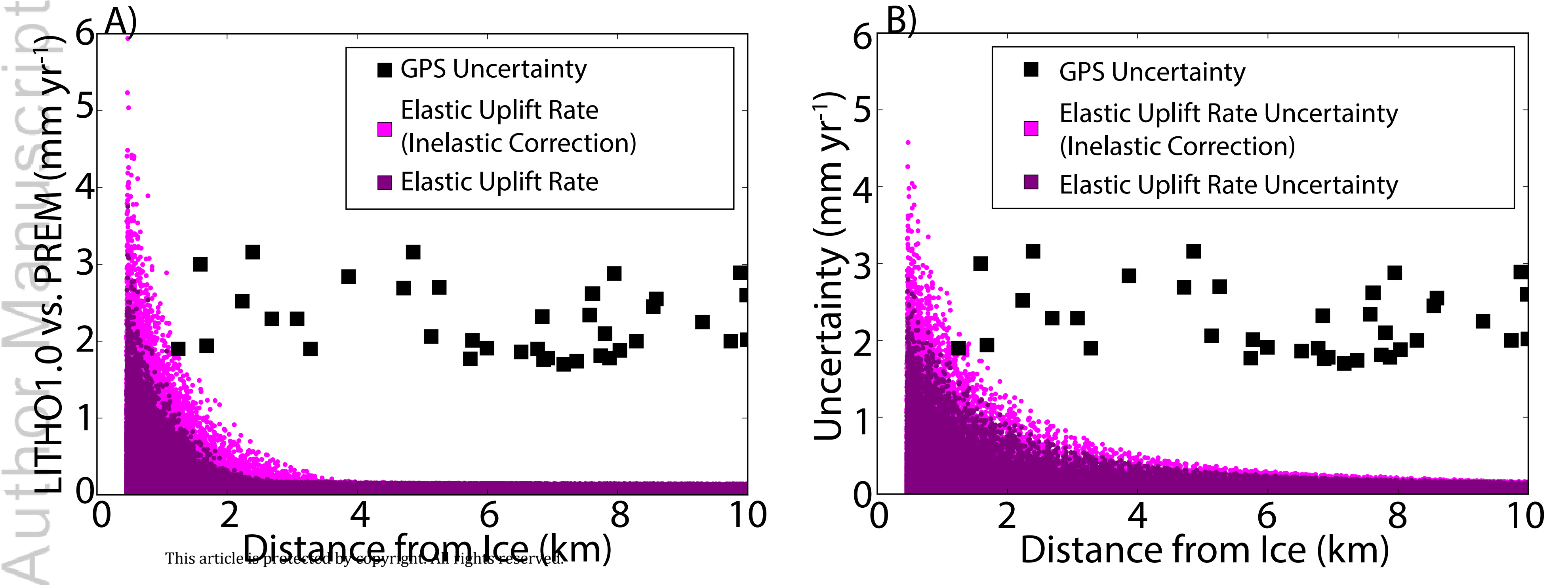




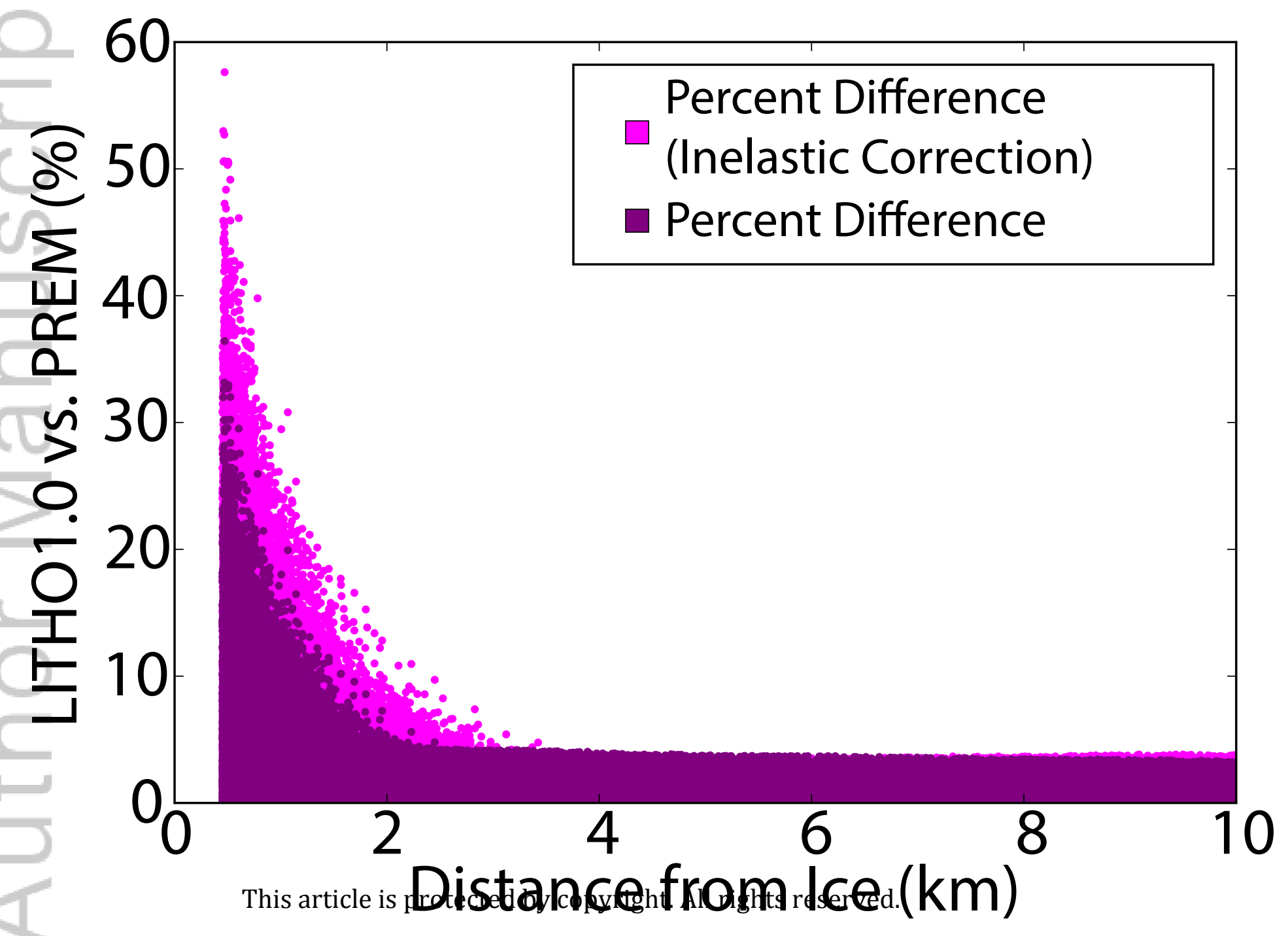




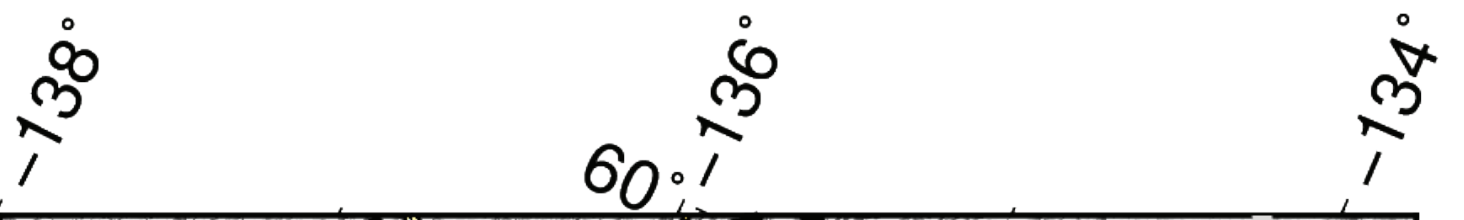

\section{作} (n)

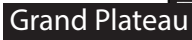
(n) 17 .

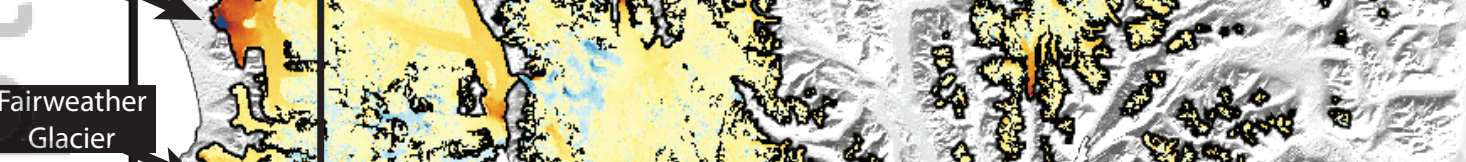

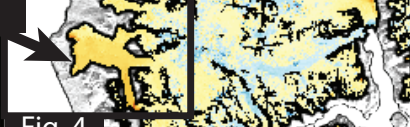

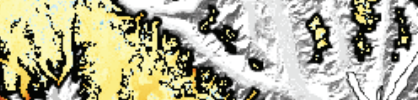

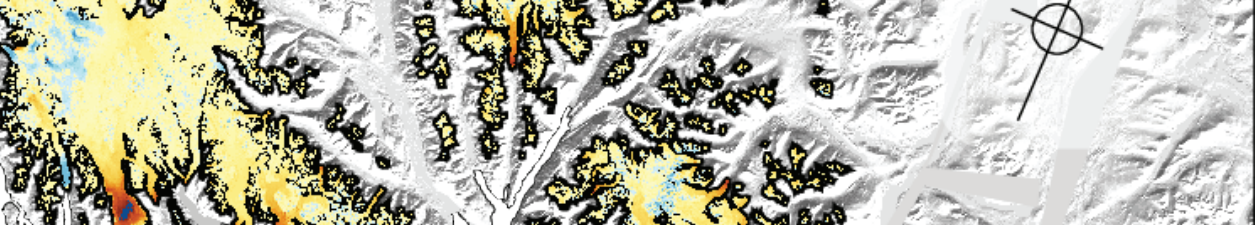
Ne. $60^{\circ}$

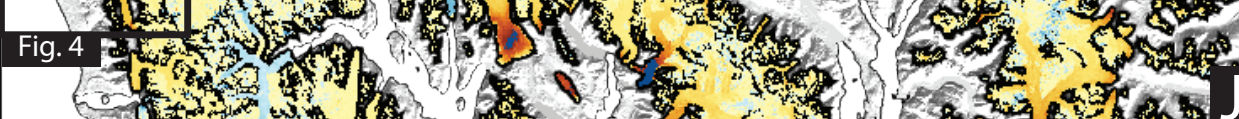

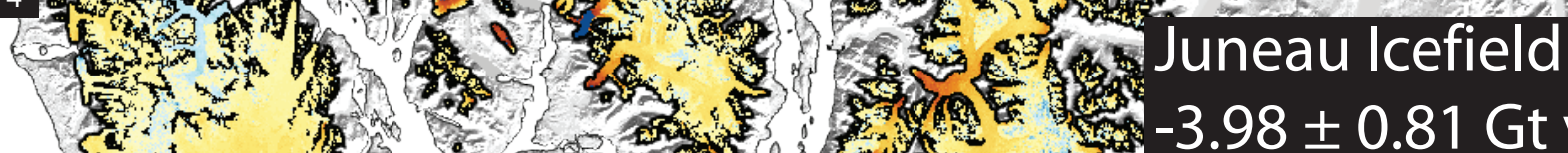

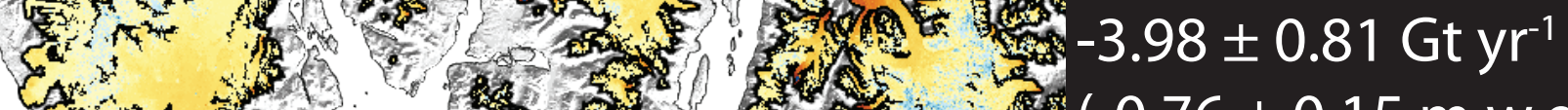
(4.

\section{Glacier Bay}

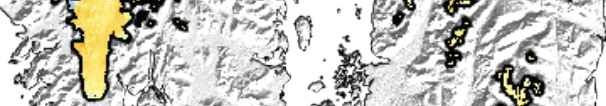

$-5.26 \pm 0.79 \mathrm{Gt} \mathrm{yr}^{-1}$ $\left(-0.76 \pm 0.11 \mathrm{~m}^{2}\right.$ w.e. $\left.\mathrm{yr}^{-1}\right)$ 的

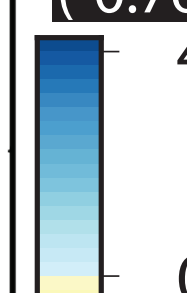

4

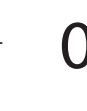

$0 \tau$ -

文

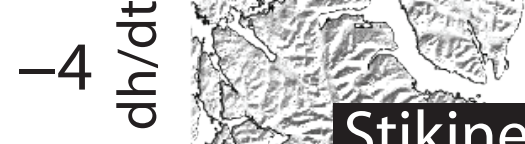

口. . Stikine lcefield ot yr ${ }^{-1}$

$-8$ s.e. A.
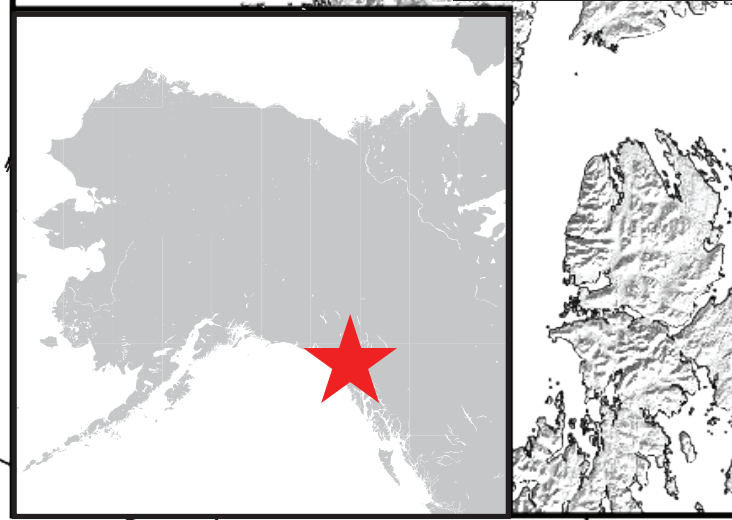
$0.08 \mathrm{~m}$ w.e.

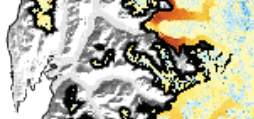

s 0

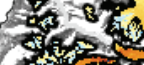

(a)

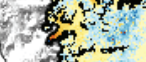

然

(i)
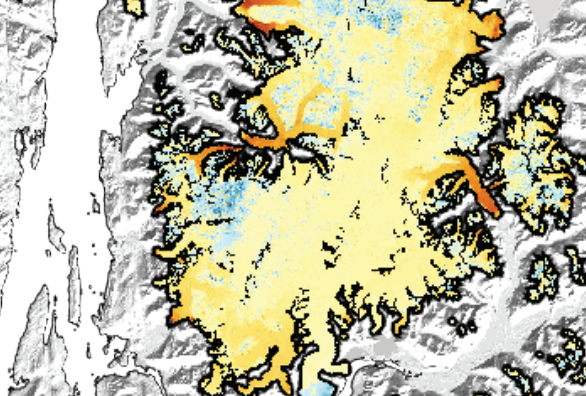

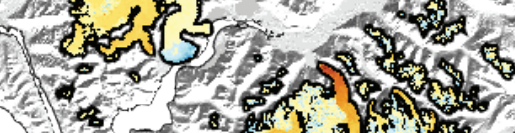

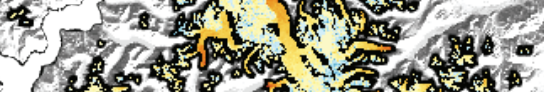

Obfor w o

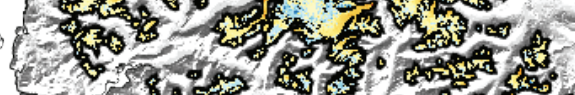

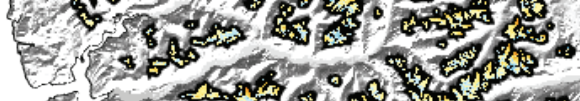

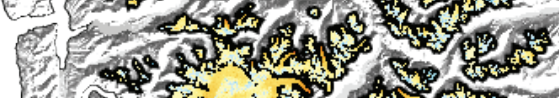

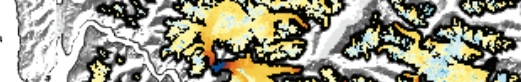

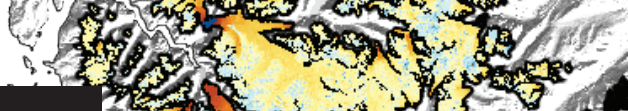

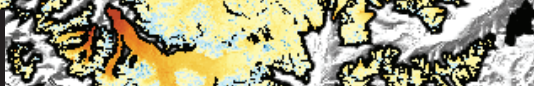
4 ticis and

as

$\left.y r^{-1}\right)$

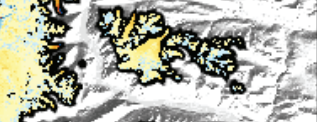

$58^{\circ}$

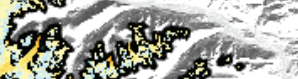

istis

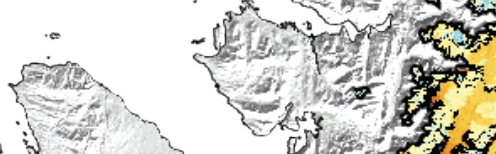

ing $\frac{10}{30}, 15$ Lof

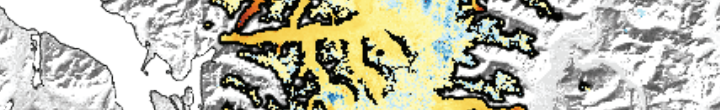
$192 v+5$ 1362 . nit. 49 is 2616

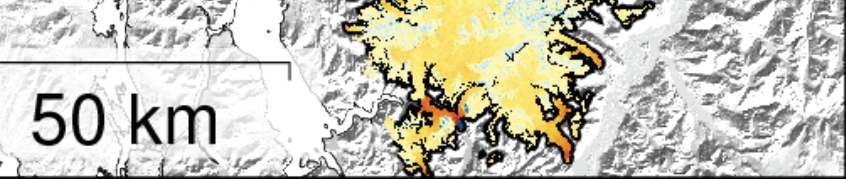

$59^{\circ}$

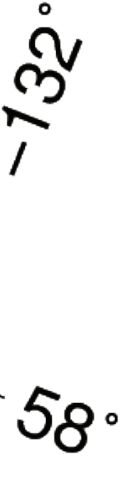




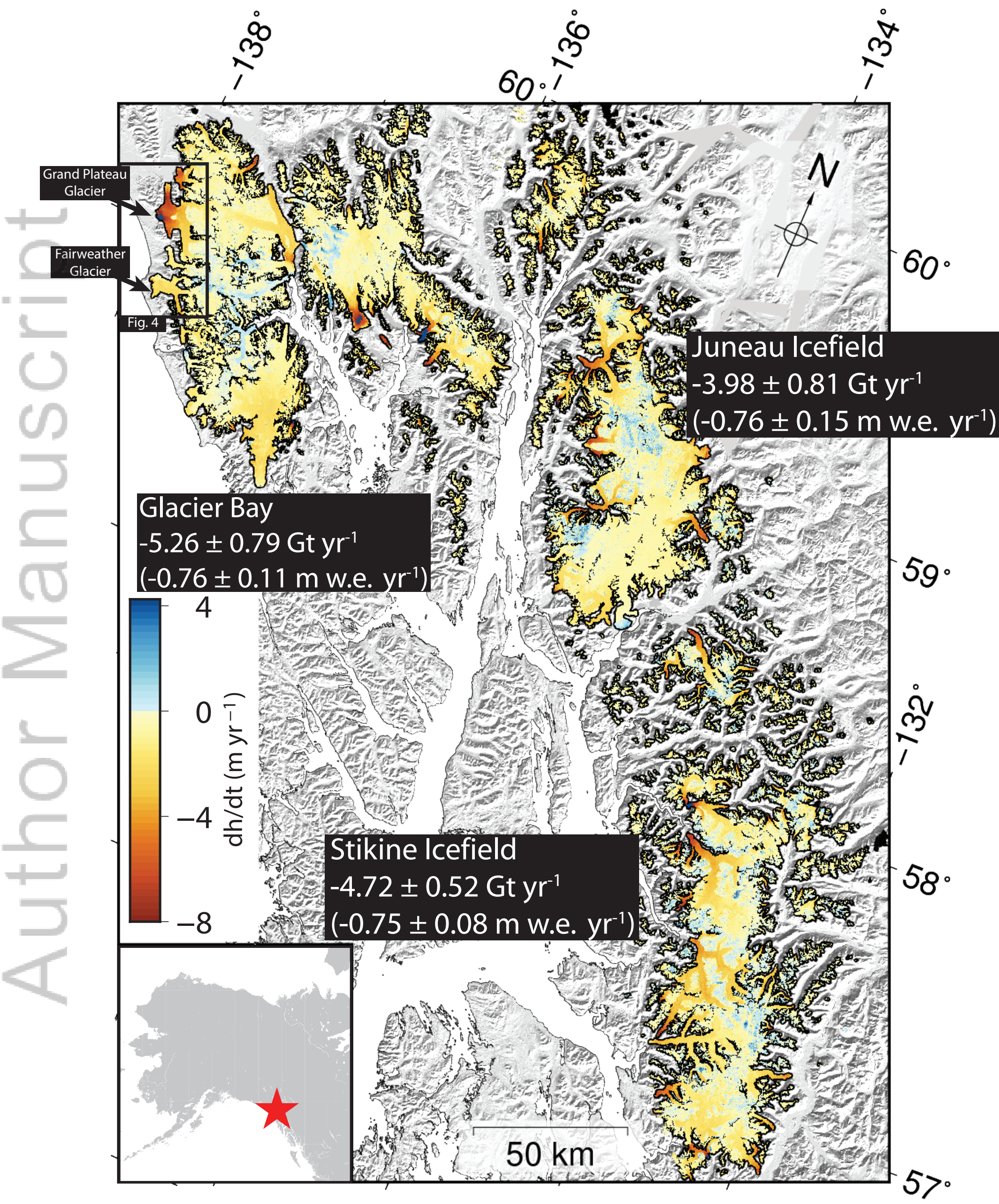




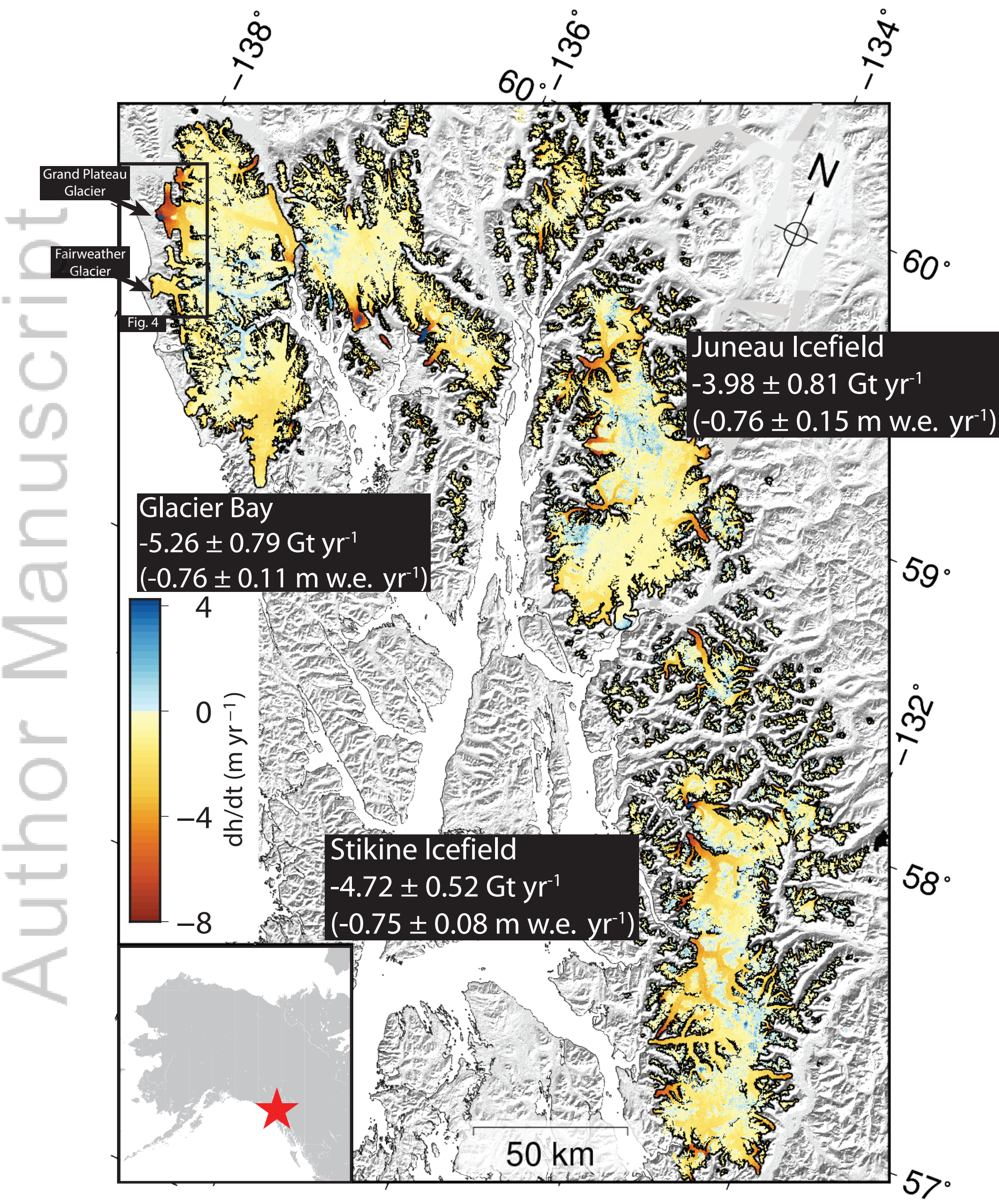




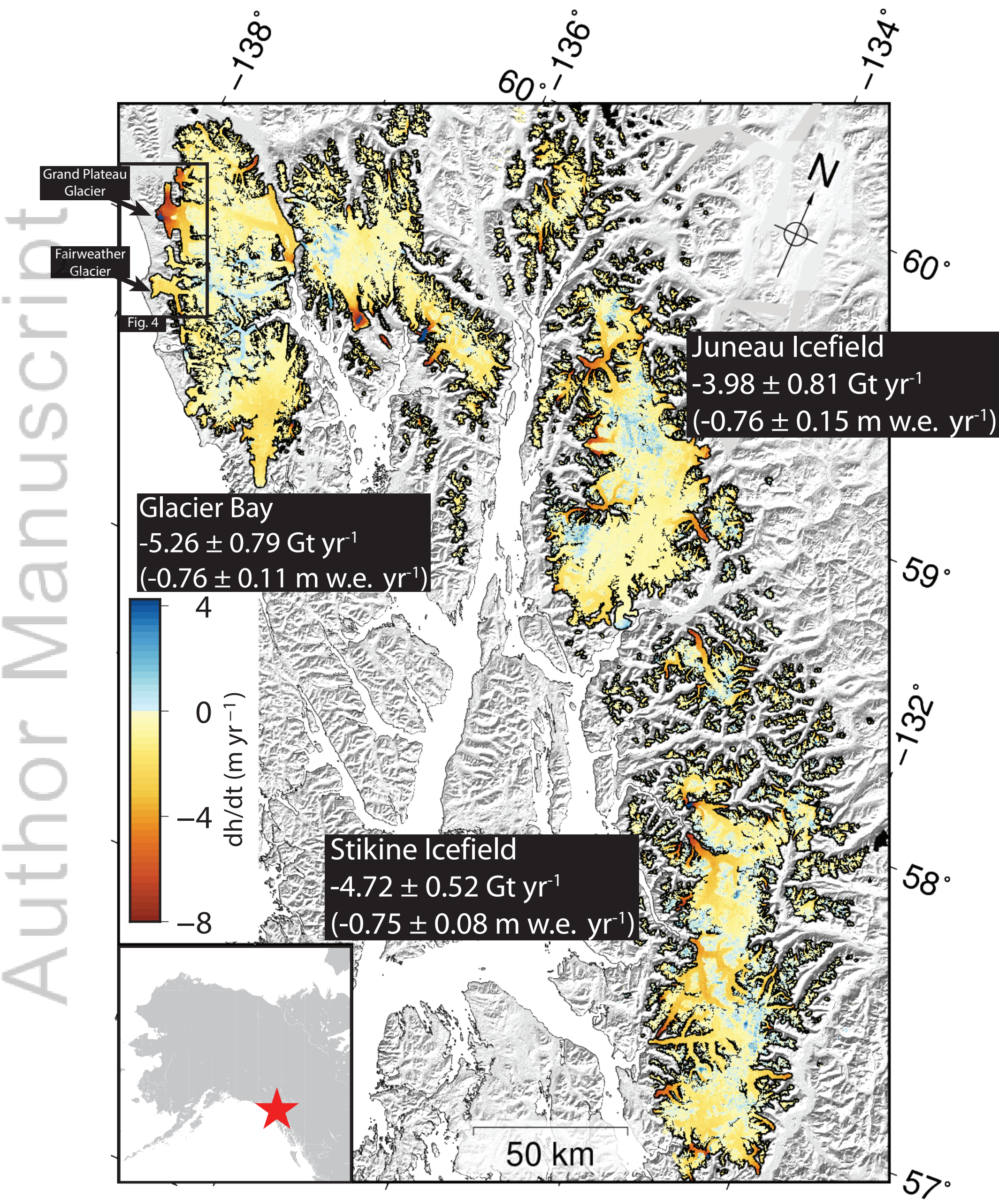




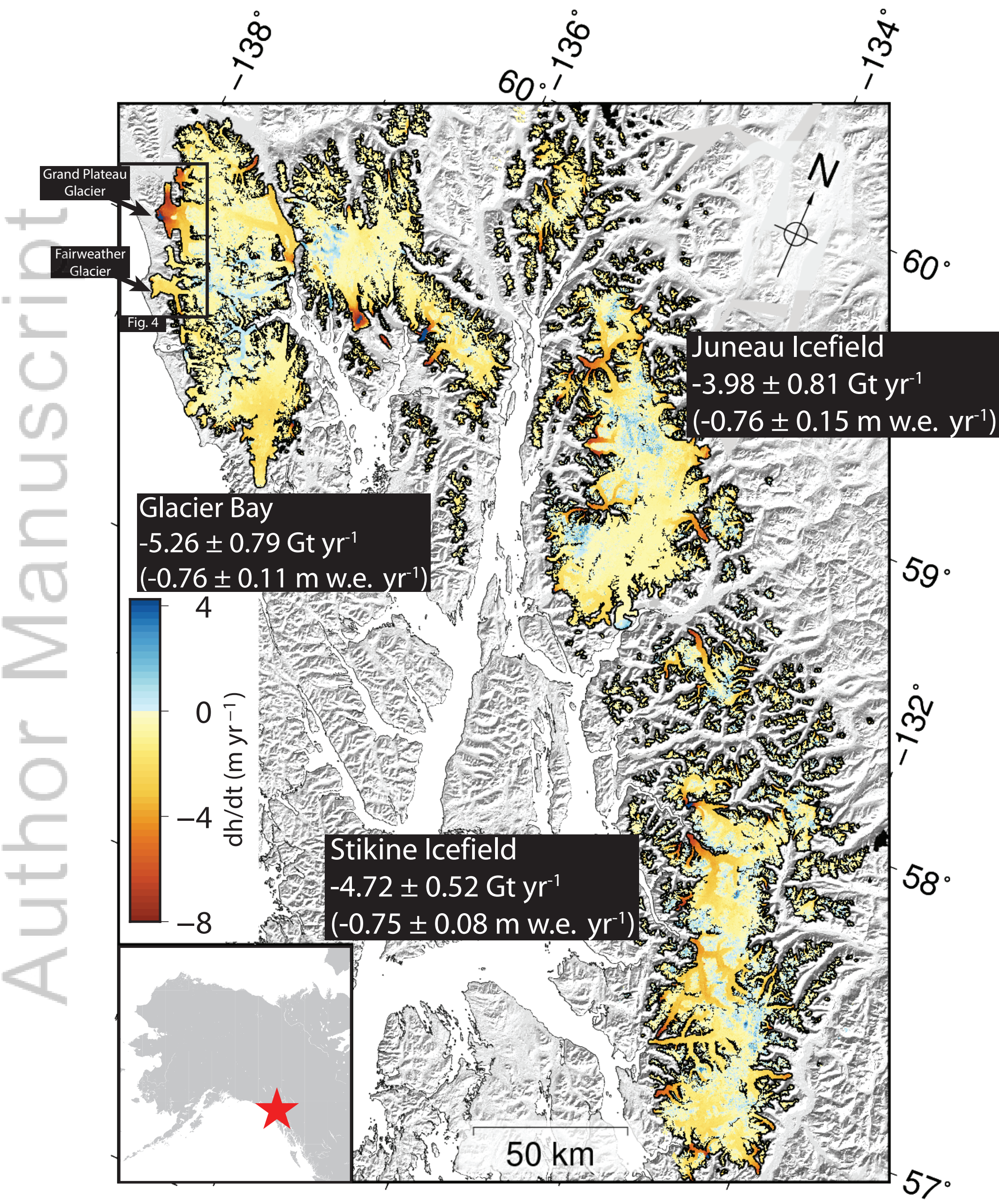




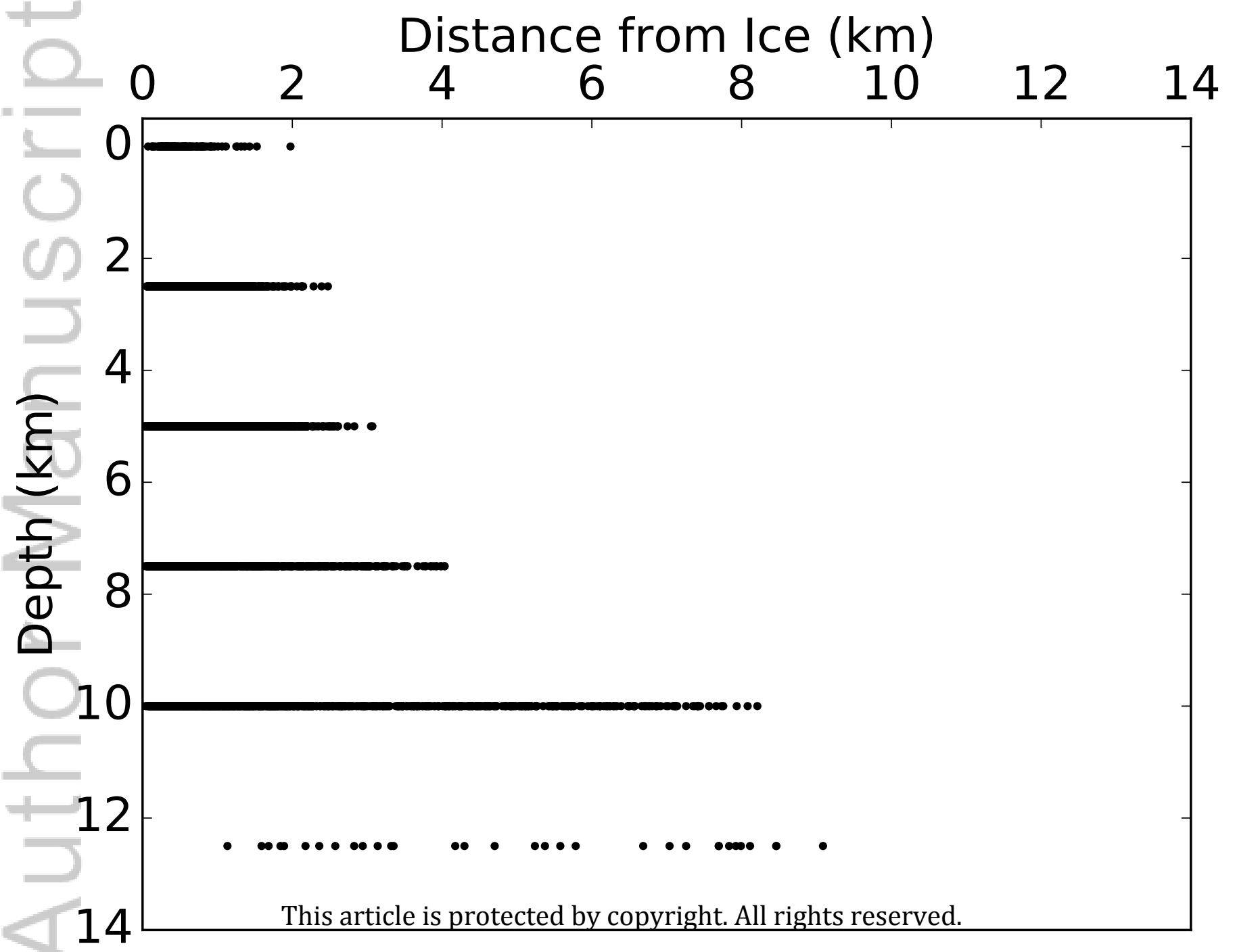




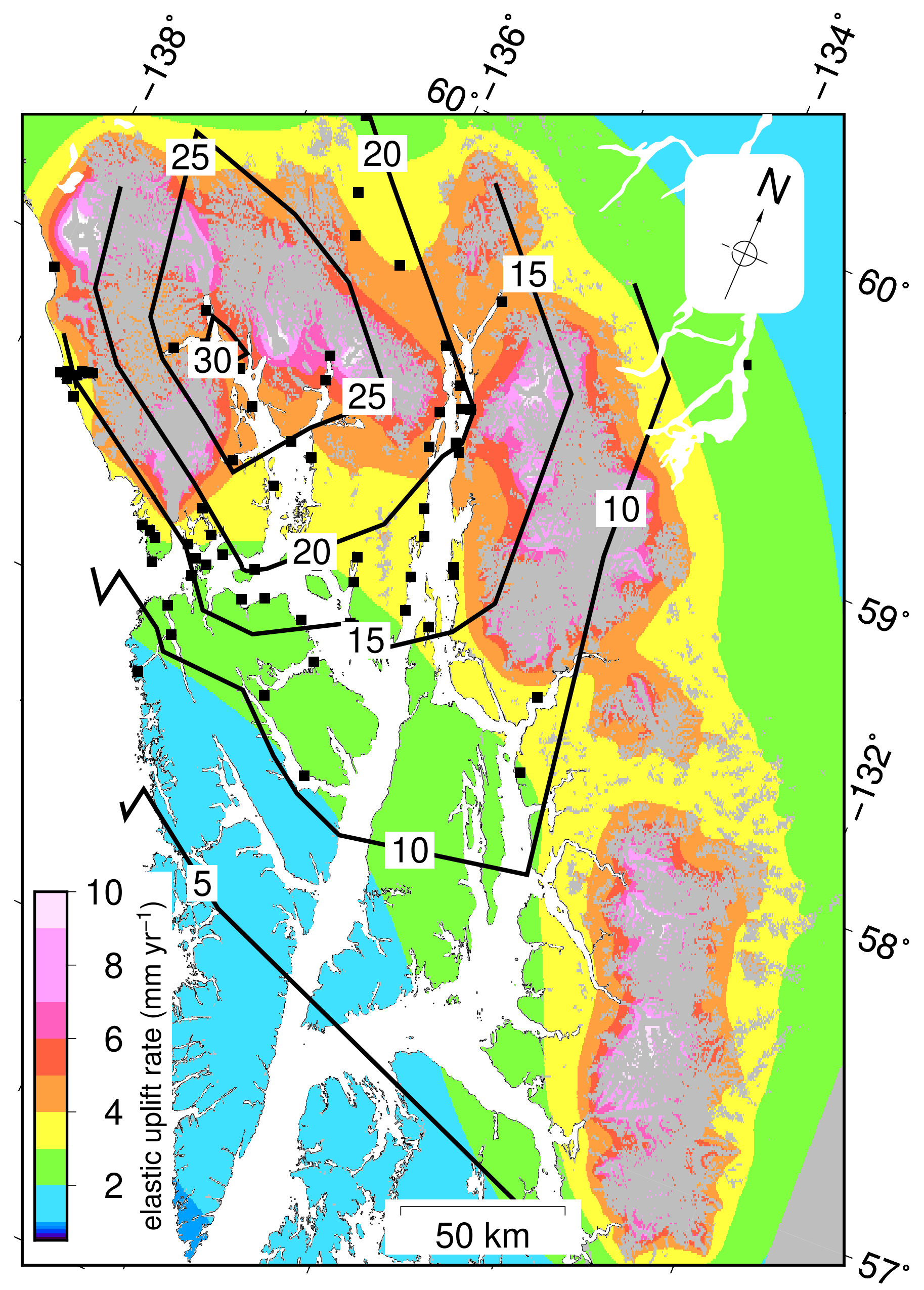

This article is protected by copyright. All rights reserved. 


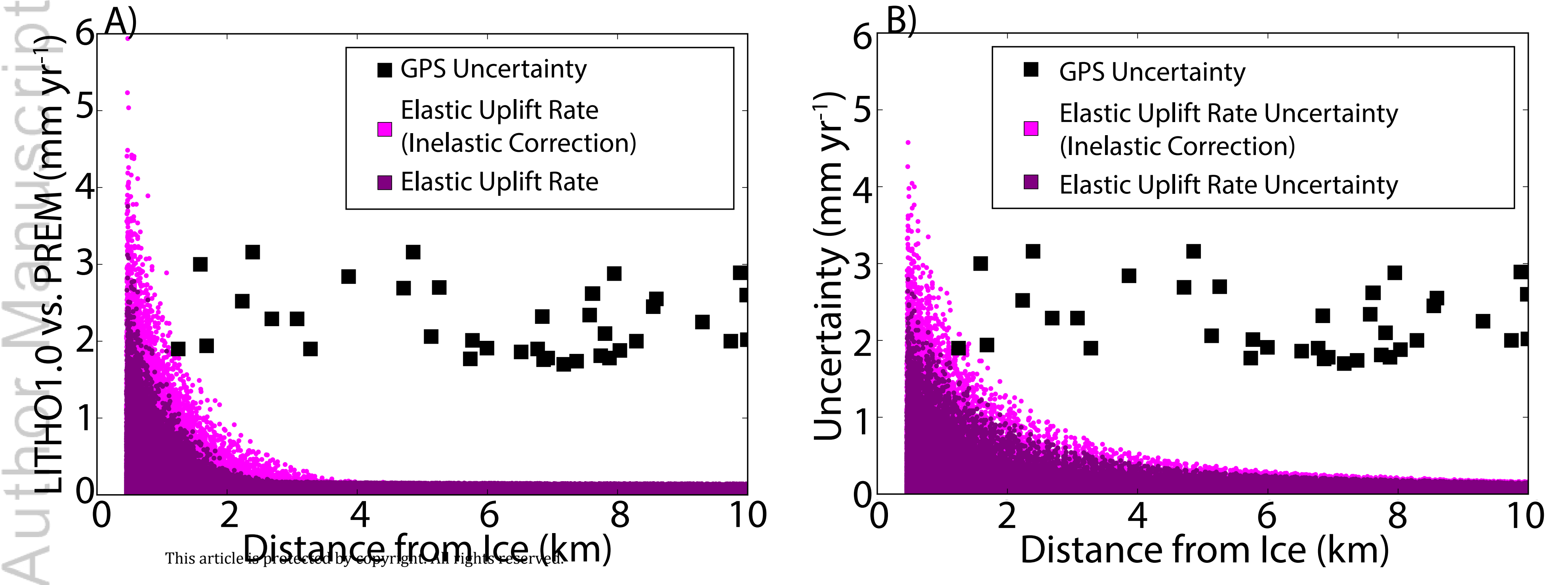




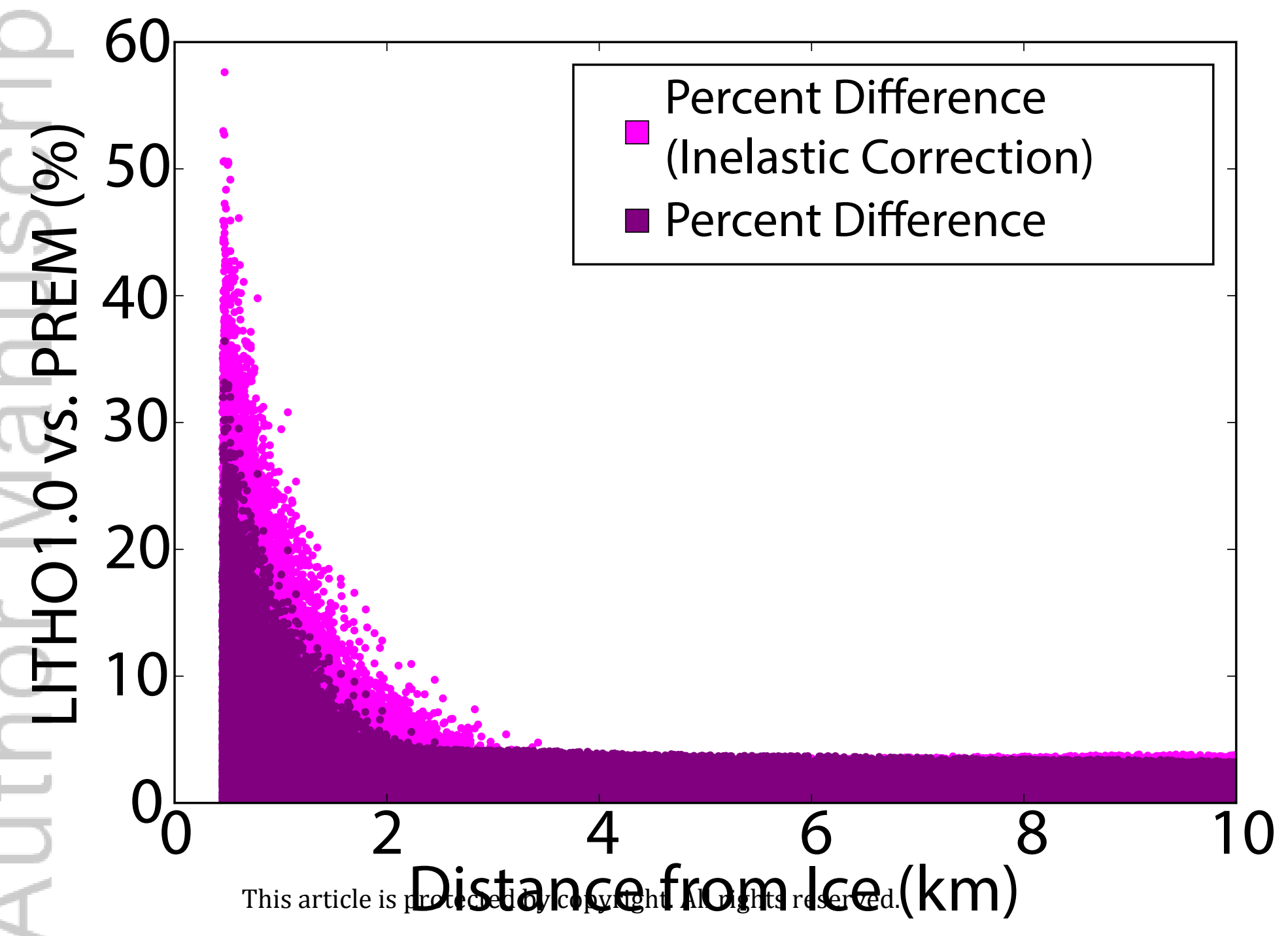

